\title{
A systematic investigation of the effects of process parameters on heat and fluid flow and metallurgical conditions during laser-based powder bed fusion of Ti6Al4V alloy
}

\section{Bayat, Mohamad; Mohanty, Sankhya; Hattel, Jesper Henri}

Published in:

International Journal of Heat and Mass Transfer

Link to article, DOI:

10.1016/j.ijheatmasstransfer.2019.05.017

Publication date:

2019

Document Version

Peer reviewed version

Link back to DTU Orbit

\section{Citation (APA):}

Bayat, M., Mohanty, S., \& Hattel, J. H. (2019). A systematic investigation of the effects of process parameters on heat and fluid flow and metallurgical conditions during laser-based powder bed fusion of Ti6Al4V alloy.

International Journal of Heat and Mass Transfer, 139, 213-230.

https://doi.org/10.1016/j.ijheatmasstransfer.2019.05.017

\section{General rights}

Copyright and moral rights for the publications made accessible in the public portal are retained by the authors and/or other copyright owners and it is a condition of accessing publications that users recognise and abide by the legal requirements associated with these rights.

- Users may download and print one copy of any publication from the public portal for the purpose of private study or research.

- You may not further distribute the material or use it for any profit-making activity or commercial gain

- You may freely distribute the URL identifying the publication in the public portal 


\title{
1 A Systematic investigation of the effects of process parameters on heat and fluid flow and 2 metallurgical conditions during laser-based powder bed fusion of Ti6Al4V alloy
}

\author{
3 Mohamad Bayat ${ }^{1, *}$, Sankhya Mohanty ${ }^{1}$ and Jesper Henri Hattel ${ }^{1}$ \\ $4 \quad{ }^{1}$ Department of Mechanical Engineering, Technical University of Denmark, building 425, room 225, Lyngby, Denmark \\ 5 "corresponding author
}

6 Abstract

\begin{abstract}
Additive manufacturing (AM) of metals faces a growing number of applications in different industries e.g. aerospace, medical, automotive, etc. Although metal AM outweighs current conventional production methods in some certain areas, the exact effect of processing conditions on the final quality and microstructure of the parts is still not well understood. An efficient way of understanding the effect of these processing conditions on a part's quality is via a calibrated and validated numerical model. Hence, in the current work a finite element model for analyzing the heat and fluid flow along with metallurgical conditions during Laser-based Powder Bed Fusion (L-PBF) of a titanium alloy has been developed and implemented in the commercial software code COMSOL Multiphysics. The thermal effect of the laser is modelled via a novel conico-Gaussian moving heat source, based on the concept of modified optical penetration depth. Analytical expressions for the geometrical distribution of the heat source are derived to obtain the heat source's effective depth. The model has been both verified and validated through mesh sensitivity analysis and comparison with experimental results. Furthermore, a detailed description about the role of the various driving forces for fluid flow has been given based on a thorough analysis using relevant dimensionless numbers. A systematic procedure to study the influence of neglecting the fluid flow inside the melt pool on the thermal field has also been devised. Moreover, a parametric study has been carried out to understand the effect of varying beam size and laser travel speed on heat and fluid flow conditions along with the final microstructures. The results show that changing the beam size or travel speed highly influences the grain sizes, dendritic growth directions and also the grain morphologies. To study the metallurgical conditions of the process, a microstructural sub-model has been developed. It is shown that by choosing different process parameters, one can manipulate the direction of the dendritic growth and change the grain sizes. Specifically, it is found that the overall effect of changing beam size on grain morphology is less pronounced than changing the travelling speed.
\end{abstract}

7 Keywords: Conical heat source, L-PBF process, heat and fluid flow, liquid metal, microstructure.

\section{Introduction}

9 In Metal Additive Manufacturing (MAM), parts are manufactured in a sequential layer by layer 10 manner. This technology is widely used in various industries such as medical, aerospace, 11 automotive, etc [1], largely due to its unique capability of producing complex parts within an 12 acceptable timespan and with low material waste (unlike subtractive manufacturing processes). In

13 L-PBF which belongs to the group of MAM technologies [2], a laser with a very tiny spot size 14 (below $200 \mu \mathrm{m}$ diameter [3]) is used as the heating source to melt down the powder particles and 15 subsequently fuse them together.

16 A schematic view of a typical L-PBF machine is shown in Figure 1. In the L-PBF process, first 17 the coating mechanism spreads a layer of fine metallic spheres (whose sizes are in the range of 20$1850 \mu \mathrm{m}$ typically [3]) on the building table. Then the laser starts to scan the predefined locations 19 based on the input CAD file [4]-[6]. In this way the powder particles get fused together and at the 20 end of the scanning step, a coherent layer of the part will be formed. Then after a cooling time of 

up (each increment is roughly equal to the thickness of a powder layer). Then the coating and scanning steps start sequentially and this cycle continues until the whole part is manufactured.
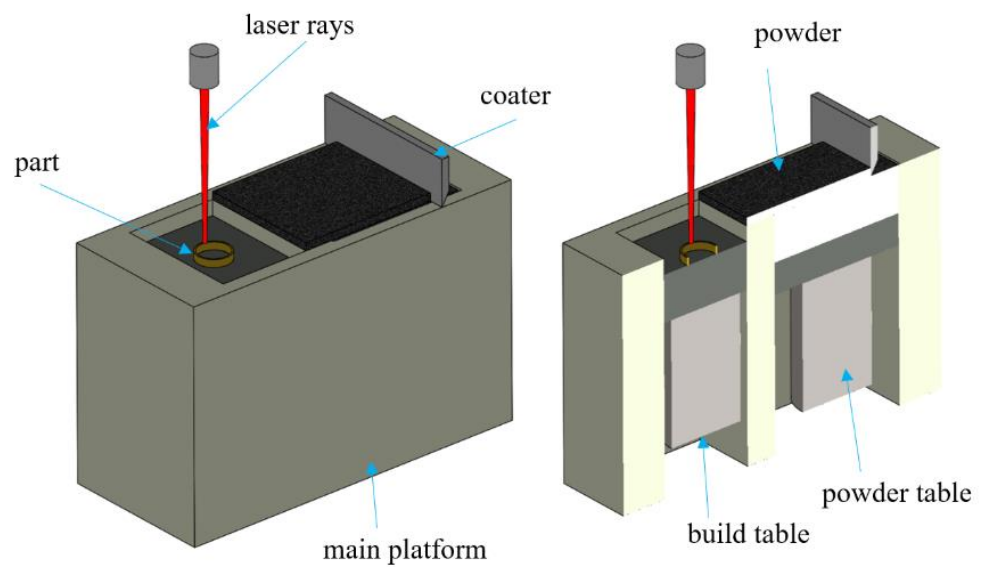

Figure 1. Schematic 3D view of a typical L-PBF machine along with the components. On the right side see the cross-section.

The L-PBF process is very fast and typically the laser scans parts with sizes of 1-30 mm, with a significant speed of 50-3000 mm. $\mathrm{s}^{-1}$ [3]. However, there still exists a lot of uncertainties about the morphology and microstructural patterns of the produced parts, because of the unsteady nature of the process. Experimental investigation of a large number of samples made with different process parameters would typically be the straightforward and conventional way of understanding the effects of these parameters on the characteristics of the parts produced [7]-[11]. Melt pool size and its geometry, location of hotspot zones, grain morphologies and void positions, would typically be the characteristics of highest importance.

There is, however, an elegant alternative way to investigate the impact of the process parameters on the mentioned part characteristics, and that is via a calibrated numerical model [12]. Such calibrated and validated model, can be implemented as a cheap, reliable and powerful tool for studying the thermal behaviour, grain morphologies and fluid dynamics inside the melt pool during the L-PBF, laser welding or any other similar laser-based process [13]-[20]. In the recent years, a substantial amount of research has been carried out in the modelling of MAM including the L-PBF process, spanning from thermal models to microstructural models, mechanical models and complex computational fluid dynamics (CFD) models [21]-[30].

Conduction heat transfer models, mainly developed in the Finite Element (FE) framework (one case with finite volume method [31]), have been widely used so far for simulation of the thermal behavior of the L-PBF process [24]-[29]. Criales et al. [24] performed a comprehensive sensitivity analysis on the effects of both material properties and process parameters on the thermal conditions during the L-PBF process. They developed a 2D heat conduction model for this purpose and showed that the powder packing's density and its reflectivity have the highest influence on the peak temperatures formed during the process [24]. Huang et al. [25] also developed an FEM-based thermal model for the Ti6Al4V alloy and studied the effects of laser input power and its scanning speed on the shape and size of the melt pool for a single track L-PBF process. Liu et al. [30] studied the effects of thermal cycling during the course of a single-track multi-layer process and found 
that the size of the melt pool increases with the number of layers, mainly due to accumulation of heat from previous layers. In a recent work, Loh et al. [26] included the volume shrinkage in their heat conduction model and showed that neglecting this effect will result in a small overestimation of peak temperatures. Also some work has been dedicated to coupled thermo-metallurgical models of MAM. Bontha et al. [32] studied the effect of varying laser input power and its scanning speed on the grain morphology of the samples produced by means of MAM. They implemented an analytical moving point source (based on the classical Rosenthal's thick plate solution) to model the thermal effects during the process. Raghavan et al. [33] and Nie et al. [34] have separately studied the effects of process parameters on the grain morphology of Nickle-based alloys in Electron Beam Melting (EBM) with each their conduction-based model.

All of the aforementioned contributions use a thermal model based on heat conduction only and without any strong argument, apart from simplicity and computational efficiency, have excluded the fluid flow from their simulations [24]-[30], [32]-[34]. However, in the recent years a number of researchers have developed multiphysics models by taking the fluid motion into account [35][38] both for MAM and welding. For example, Leitz et al. [39] have developed a multiphysics numerical model based on the FEM and included the fluid motion in their calculations. In another recent work, Lee and Zhang [40] developed a multiphysics numerical model in the Finite Volume Method (FVM) framework and considered the deformation of the exposed surface of the metal as well. The mentioned thermo-fluid models mostly focused on just one single set of process parameters and have not as such been used for studying the metallurgical characteristics of the samples [22], [35]-[38], except for [40] and [41] where the authors showed that the grain morphology would remain columnar for their specific L-PBF process involving the Inconel 718 alloy and Ti6Al4V, respectively.

In this work, a thermo-fluid-metallurgical model based on the FEM framework has been developed in COMSOL Multiphysics for the single track L-PBF process of Ti6Al4V. The model includes all modes of heat transfer, namely conduction, convection and radiation. To model the fluid flow during the solidification, solidification drag forces have been inserted as volumetric forces into the Navier-Stokes equations. The thermo-capillary effect has been taken into account as well. Furthermore, a novel moving volumetric heat source based on the concept of optical penetration depth has been introduced and by just adjusting one parameter associated with the shape of the heat source, the model can be easily calibrated. The results of the current model have both been numerically verified and experimentally validated. A thorough analysis on the role of the different driving forces on the fluid flow and the mode of heat transfer on the temperature fields has been carried out by means of dimensionless numbers. Moreover, a parametric study has been performed to analyze the impact of varying the laser beam radius and its travelling speed on melt pool size and geometry, fluid dynamics, grain morphology, solidification patterns and dendritic growth directions. For this, a microstructural sub-model has been developed and coupled to the thermofluid model.

\section{Finite element model}

The developed numerical model is based on the FEM framework and has been implemented in COMSOL Multiphysics 5.3a. The domain is considered to be a rectangular parallelepiped with 3 
93 mm length, $0.75 \mathrm{~mm}$ width and $1.5 \mathrm{~mm}$ height, see Figure 2. The model is meshed with tetrahedral 94 elements and as shown in Figure 2, the laser starts scanning the powder layer from the point " $S$ " 95 all the way to the point " $F$ ". The powder layer with thickness $\chi$ (seen on figure 3 ) is situated right 96 above the bulk material and has its top boundary exposed to the surroundings. Since the area close 97 to the laser path experiences extremely large spatio-temporal changes in both temperature and fluid 98 flow, it is meshed with a much finer mesh.

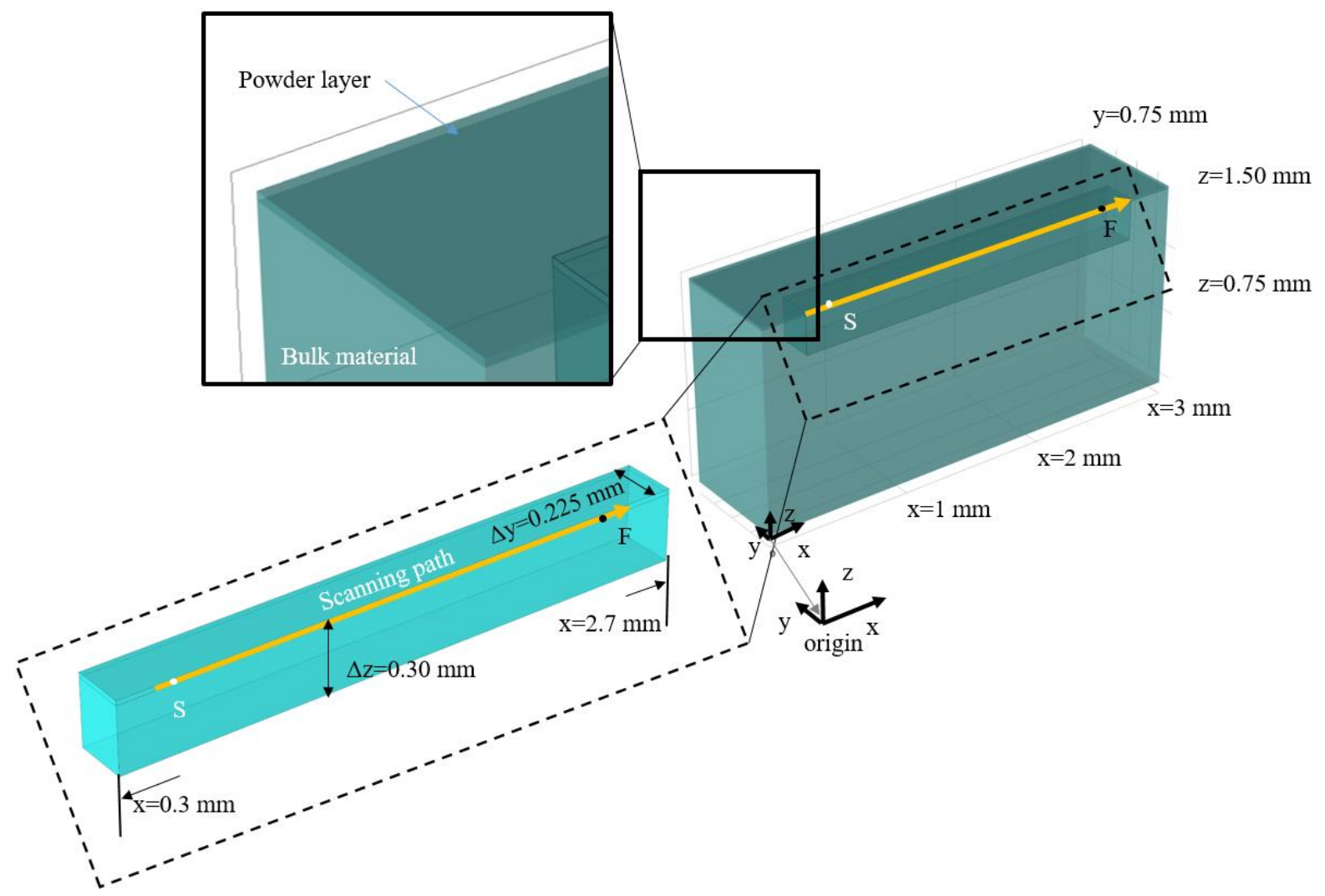

Figure 2. Model geometry along with the part dimensions. The scanning line starts from point "S" all the way to point "F" along the scanning path arrow shown in orange color. On the top of the bulk material the powder layer is set. The parallelepiped shown in cyan blue is the zone which is meshed with very fine mesh elements. The symmetry plane is the $y=0$ plane where the symmetry boundary condition is set as well.

104 Due to the symmetrical nature of the problem shown in Figure 2, a symmetry boundary condition 105 is used on the $\mathrm{y}=0$ plane for both thermal and fluid dynamics models. The main assumptions made are listed below

- The flow is assumed to be incompressible.

112 - Mass loss due to evaporation is ignored. 
113 - Mass-averaged thermo-physical properties are used.

\section{2.1. Heat transfer model}

115 The transient temperature distribution over the computational domain can be found by solving the 116 general energy equation accounting for both conduction and convection [42], [43].

$$
\begin{aligned}
\frac{\partial}{\partial t}\left(\rho C_{p} T\right)+ & \frac{\partial}{\partial x_{j}}\left(\rho C_{p} T u_{j}\right) \\
& =\frac{\partial}{\partial x_{j}}\left[k\left(\frac{\partial T}{\partial x_{j}}\right)\right]-\rho \Delta H_{f l}\left[\frac{\partial}{\partial t}\left(f_{l}\right)+\frac{\partial}{\partial x_{j}}\left(f_{l} u_{j}\right)\right]+\dot{Q}_{\forall}^{\prime \prime \prime}
\end{aligned}
$$

117 The velocity vector is denoted $u_{\mathrm{i}}\left(\mathrm{m} . \mathrm{s}^{-1}\right)$ in equation (1) while $C_{p}\left(\mathrm{~J}_{\mathrm{kg}} \mathrm{kg}^{-1} \cdot \mathrm{K}^{-1}\right)$ and $\rho\left(\mathrm{kg} \cdot \mathrm{m}^{-3}\right)$ are

118 specific heat capacity and density of the metal, respectively. $k\left(\mathrm{~W} \cdot \mathrm{m}^{-1} \cdot \mathrm{K}^{-1}\right)$ and $\Delta H_{f l}\left(\mathrm{~J}_{\mathrm{kg}} \mathrm{kg}^{-1}\right)$ are 119 thermal conductivity and latent heat of fusion and $Q{ }^{\prime \prime}{ }_{V}\left(\mathrm{~W} \cdot \mathrm{m}^{-3}\right)$ is the volumetric heat source 120 caused by the laser irradiation. $f_{l}$ is the fraction of the liquid phase which for simplicity is assumed 121 to be a linear function of temperature.

$$
f_{l}=\left\{\begin{array}{cc}
1 & T \geq T_{l} \\
\left(T-T_{\text {sol }}\right) /\left(T_{\text {liq }}-T_{\text {sol }}\right) & T_{s}<T<T_{l}, \\
0 & T \leq T_{s}
\end{array}\right.
$$

122 where $T_{s}$ and $T_{l}$ respectively stand for solidus and liquidus temperatures. The required thermo123 physical properties of Ti6Al4V are given in Table 1.

124 Table 1. Thermo-physical properties of Ti6Al4V for the CFD calculations [25], [38], [32].

\begin{tabular}{llll}
\hline Property & Symbol & Value & Unit \\
\hline Solidus temperature & $T_{s o l}$ & 1893.2 & $(\mathrm{~K})$ \\
Liquidus temperature & $T_{l i q}$ & 1927.2 & $(\mathrm{~K})$ \\
Solid specific heat capacity & $C_{p s}$ & 543 & $\left(\mathrm{~J} . \mathrm{kg}^{-1} \cdot \mathrm{K}^{-1}\right)$ \\
Liquid specific heat capacity & $C_{p l}$ & 750 & $\left(\mathrm{~J} . \mathrm{kg}^{-1} \cdot \mathrm{K}^{-1}\right)$ \\
Viscosity at melting point & $\mu$ & 0.005 & $(\mathrm{~Pa} \cdot \mathrm{s})$ \\
Temperature dependency of surface tension & $\gamma$ & -0.0002 & $\left(\mathrm{~N} \cdot \mathrm{m}^{-1} \cdot \mathrm{K}^{-1}\right)$ \\
Solid thermal conductivity & $k_{s}$ & 13 & $\left(\mathrm{~W} \cdot \mathrm{m}^{-1} \cdot \mathrm{K}^{-1}\right)$ \\
Liquid thermal conductivity & $k_{l}$ & 33 & $\left(\mathrm{~W} . \mathrm{m}^{-1} \cdot \mathrm{K}^{-1}\right)$ \\
Latent heat of fusion & $\Delta H_{f l}$ & 280000 & $\left(\mathrm{~J} . \mathrm{kg}^{-1}\right)$ \\
Laser absorption coefficient & $\alpha$ & 0.3 & $(-)$
\end{tabular}


$\begin{array}{llll}\text { Ambient convective heat transfer coefficient } & h_{\infty} & 30 & \left(\mathrm{~W} \cdot \mathrm{m}^{-2} \cdot \mathrm{K}^{-1}\right)\end{array}$

125 In this work mass-averaged material properties have been used for the calculations [21]. For the 126 bulk material, the effective values of density, specific heat capacity and thermal conductivity can

127 be determined with a simple mass-averaging between liquid and solid properties as shown in

128 equations (3)-(5):

$$
\begin{aligned}
& \rho_{\text {bulk }}=f_{l} \rho_{l}+\left(1-f_{l}\right) \rho_{s^{\prime}} \\
& C_{P, \text { bulk }}=\frac{1}{\rho_{\text {bulk }}}\left(f_{l} \rho_{l} C_{P l}+\left(1-f_{l}\right) \rho_{s} C_{P s}\right), \\
& k_{\text {bulk }}=f_{l} k_{l}+\left(1-f_{l}\right) k_{s} .
\end{aligned}
$$

129 Similarly the effective thermal properties of the powder layer can be found by mass averaging of 130 bulk metal and air properties, as well:

$$
\begin{aligned}
& \rho_{\text {powder }}=\phi \rho_{\text {air }}+(1-\phi) \rho_{\text {bulk' }}, \\
& C_{P, \text { powder }}=\frac{1}{\rho_{\text {powder }}}\left(\phi \rho_{\text {air }} C_{P, \text { air }}+(1-\phi) \rho_{\text {bulk }} C_{P, b u l k}\right), \\
& k_{\text {powder }}=(1-\phi)^{2} k_{\text {bulk }},
\end{aligned}
$$

131 where $\phi$ in equations (6)-(8) is the initial packing porosity of the powder layer and in this study is 132 assumed to be 0.4 [24], [25]. The subscript ( )air stands for air properties in the mentioned equations.

\section{Thermal boundary conditions}

134 The boundary conditions required for the thermal calculations are shown in Figure 3. According 135 to this figure, the top boundary is subjected to radiation and convection via the ambient, i.e.:

$$
-k \frac{\partial T}{\partial z}=h_{\infty}\left(T-T_{\infty}\right)+\varepsilon \sigma\left(T^{4}-T_{\infty}^{4}\right), \quad z=1.5 m m \text { or } \partial \Omega_{t o p}
$$

136 The $h_{\infty}\left(\mathrm{W} . \mathrm{K}^{-1} \cdot \mathrm{m}^{-2}\right)$ and $T_{\infty}$ are the ambient convection heat transfer coefficient (found for the case 137 of natural convection from a hot lower surface [44]) and the surrounding temperature respectively. $138 \varepsilon$ and $\sigma\left(\mathrm{W} \cdot \mathrm{m}^{-2} \cdot \mathrm{K}^{-4}\right)$ are surface emissivity and the Stephan-Boltzmann constant. As shown in

139 Figure 3, the bottom boundary condition is set to be adiabatic in order to represent the very low 140 thermal gradients at this distant boundary as compared to where the laser affects the material, i.e.:

$$
-k \frac{\partial T}{\partial z}=0, \quad z=0.0 \text { or } \partial \Omega_{\text {bottom }}
$$




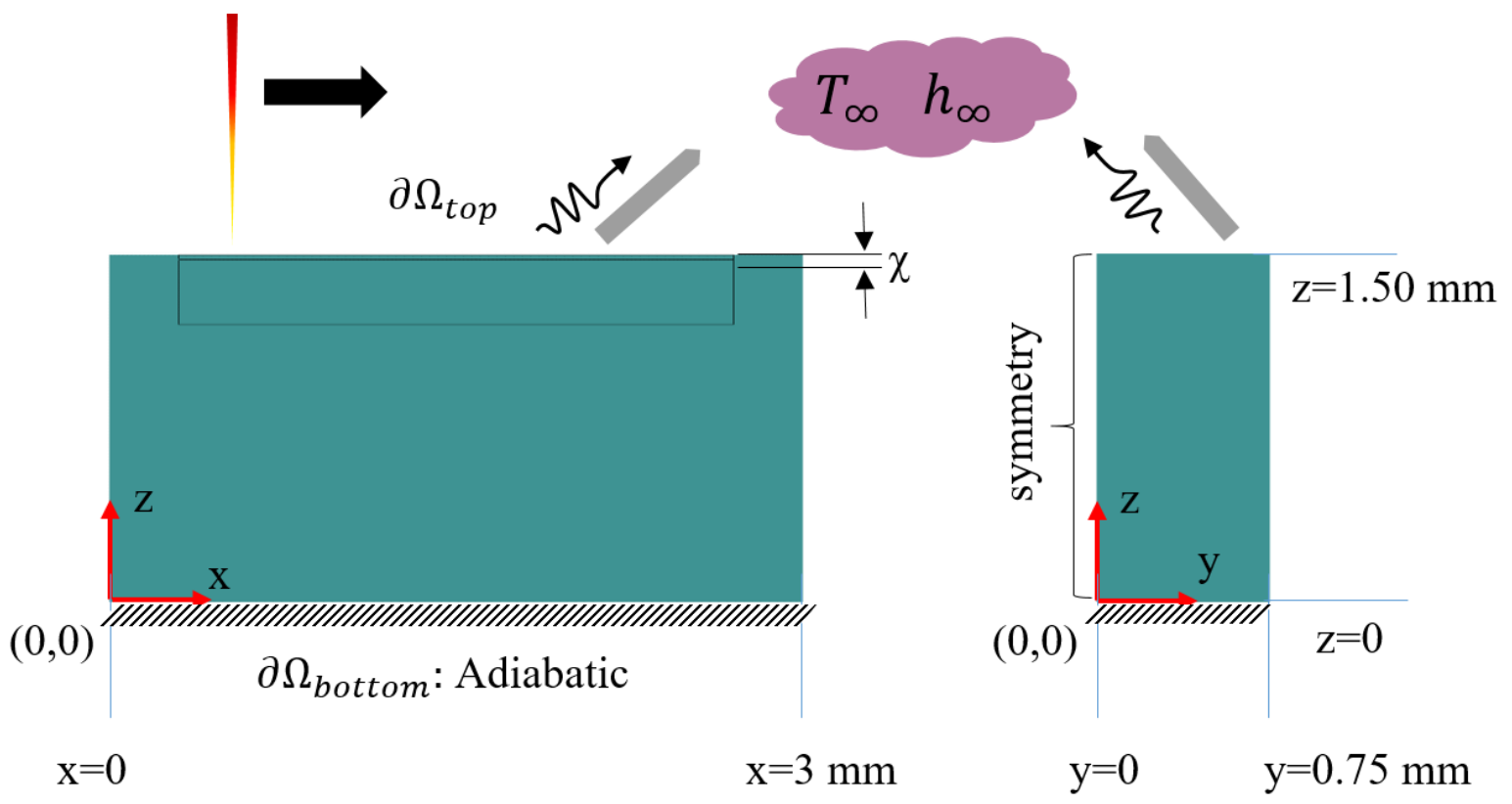

142 Figure 3. Thermal boundary conditions for the FE model. The bottom boundary is adiabatic and the top boundary transfers heat via 143 convection and radiation towards the ambient. The left plane at $\mathrm{y}=0$ on the $\mathrm{yz}$ plane shown on the right side of the figure is a 144 symmetry boundary condition. The thickness of the powder layer on the top is denoted $\chi$.

\section{Initial condition}

146 The initial temperature of both the powder layer and the bulk material is set to be $300 \mathrm{~K}$ with a 147 uniform distribution.

$$
T(x, y, z, t)=300, t=0.0 \&(x, y, z) \in \Omega_{\text {bulk }} \cup \Omega_{\text {powder }}
$$

$148 \Omega$ stands for the computational domain whereas $\partial \Omega$ denotes the corresponding boundaries of that 149 domain.

\section{$150 \quad$ 2.2. Conical equivalent heat source}

151 In order to model the laser effect on the material, several options exist for MAM and welding 152 simulations, such as moving point sources [32], moving surface heat flux [45], moving volumetric 153 heat source [46], the ray-tracing method [40], etc. In this work a volumetric heat source with a 154 conico-Gaussian distribution is introduced which is based on the concept of Optical Penetration 155 Depth (OPD) [47]. The OPD concept is based on the fact that the laser rays in laser-based MAM 156 can infiltrate to a certain depth into the powder layer, this way resulting in a heat generation in the 157 domain up to a certain depth from the top surface [47]. The original OPD method was introduced 158 for pure conduction problems and assumes a Gaussian spatial (in x-y plane) distribution with a 159 uniform vertical (along $\mathrm{z}$ ) distribution for a finite depth which is defined as the OPD. A schematic 160 view of the aforementioned cylindrical-OPD heat source is shown in Figure 4 (a). Although the cylindrical OPD might give satisfactory results for pure conduction problems, in CFD models with 163 [48]-[50]. Hence, in the present work, a modified version of the OPD heat source is developed 
164 which has a Gaussian planar (x-y) and a linear vertical distribution (along the depth) as shown 165 schematically in Figure 4 (b).

(a)

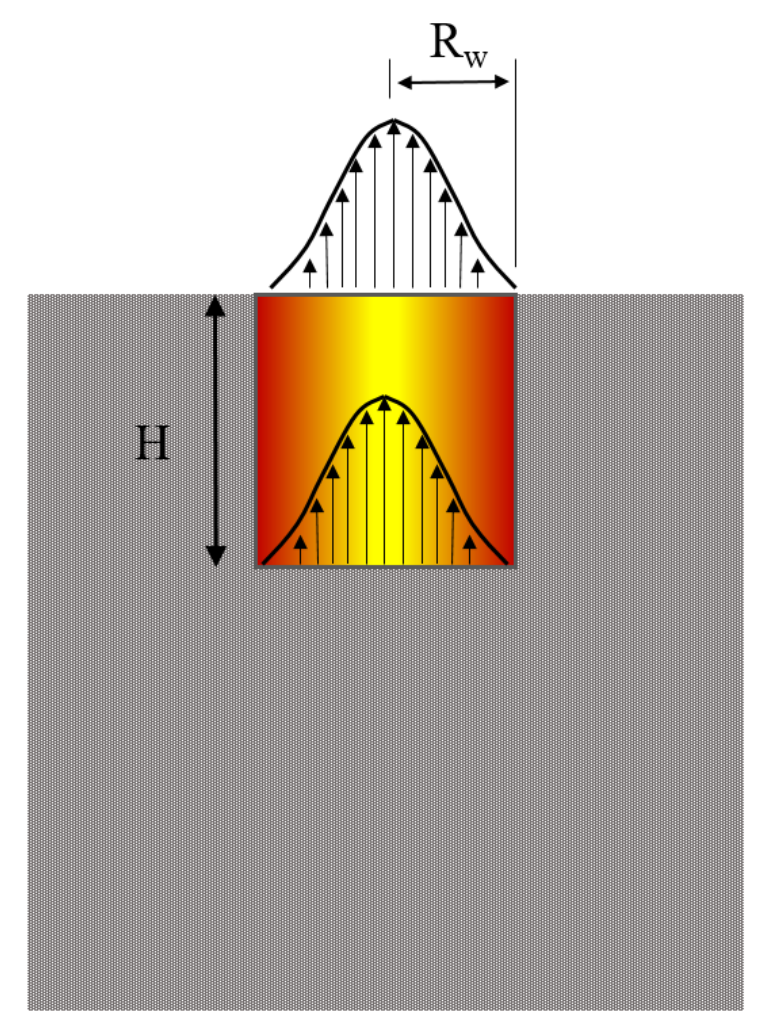

(b)

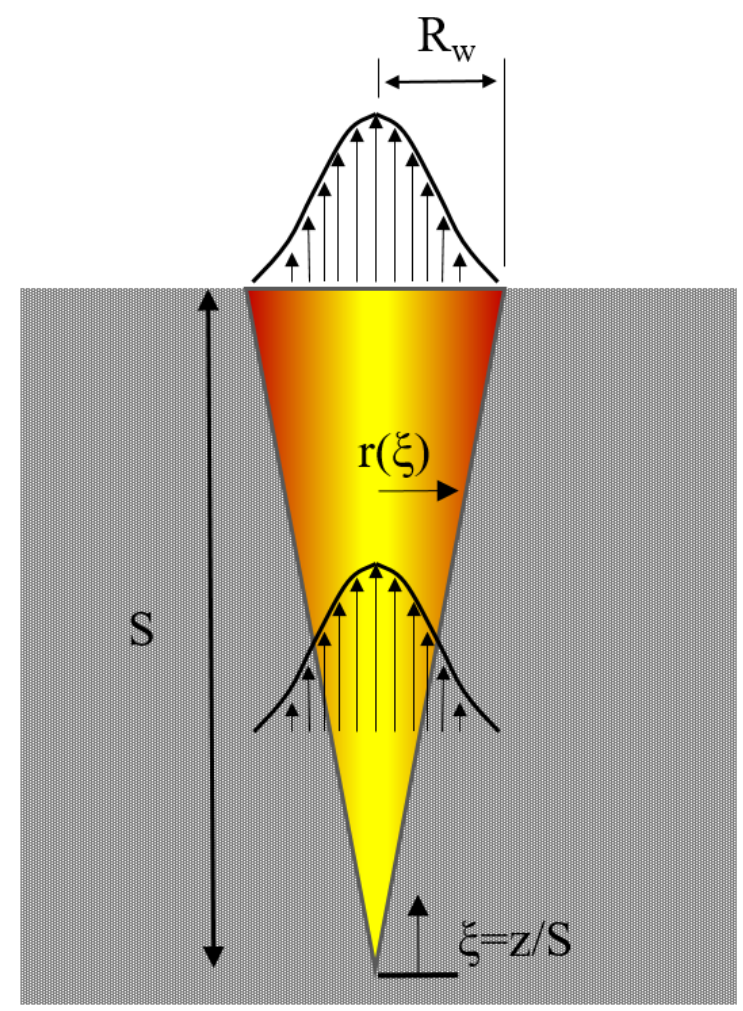

166

167

168

169

170

171

Figure 4. The schematic view of (a) cylindrical OPD and (b) conical OPD. Note that the planar distribution for both cases remains Gaussian and for the case (b) the heat is just generated until the fridges of the heat source which is denoted by $r(\xi)$. Both (a) and (b) release the same amount of heat as the input energy $\alpha \mathrm{P}_{\mathrm{w}}$.

The necessary requirement for this volumetric heat source is that it should release the same amount of energy as the laser input energy, which is $\alpha P_{w}$, i.e.:

$$
\iiint_{V_{h}} \dot{Q}_{\forall}^{\prime \prime \prime} d V=\alpha P_{w}
$$

172 and the Gaussian heat flux is given by

$$
\dot{q}_{\text {laser }}^{\prime \prime}=\frac{2 \alpha P_{w}}{\pi R_{w}^{2}} e^{-\frac{2\left(x^{2}+y^{2}\right)}{R_{w}^{2}}}
$$

173 where $q_{\text {laser }}\left(\mathrm{W} . \mathrm{m}^{-2}\right)$ in equation (13) is the Gaussian heat flux and $R_{w}(\mathrm{~m})$ is the distance from the 174 center of the heat source of which the heat flux reaches $e^{-2}$ of its peak value. Now, the cylindrical175 OPD heat source is simply found by dividing the Gaussian heat flux by the OPD depth which 176 according to Figure 4 (a) is denoted $H(\mathrm{~m})$. 


$$
\dot{Q}_{c y l}^{\prime \prime \prime}=\frac{\dot{q}_{\text {laser }}^{\prime \prime}}{H}=\frac{2 \alpha P_{w}}{H \pi R_{w}^{2}} e^{-\frac{2\left(x^{2}+y^{2}\right)}{R_{w}^{2}}} .
$$

177 The subscript ( ) cyl stands for cylindrical in equation (14). The conical-OPD heat source is defined 178 by multiplying the cylindrical-OPD heat source introduced in equation (14) by a dimensionless 179 vertical distribution function $\xi(-)$ in which the $\xi$ is a dimensionless coordinate from the bottom of 180 the conical heat source towards the top plane, as shown in Figure 4 (b).

$$
\begin{aligned}
& \xi=z / S \\
& \dot{Q}_{\text {cone }}^{\prime \prime \prime}=\frac{2 \alpha P_{w}}{H \pi R_{w}^{2}} e^{-\frac{2\left(x^{2}+y^{2}\right)}{R_{w}^{2}}} \cdot \xi
\end{aligned}
$$

$181 z(\mathrm{~m})$ in equation (15) is assumed to be zero at the bottom of the heat source and $S$ at its top and is 182 considered as a relative coordinate, which will be used later on for integration. Now in order to 183 find the relation between the cylindrical and conical OPD depths, respectively denoted by $H$ and $184 S$, one must set the volume integral of equation (16) equal $\alpha P_{w}$.

$$
\iiint_{V_{\text {cone }}} \dot{Q}_{\text {cone }}^{\prime \prime \prime} d V=\alpha P_{w}
$$

185 where $V_{\text {cone }}$ stands for the domain inside the conical OPD. Now we set the bounds of the integral 186 in equation (17), i.e.:

$$
\iiint_{V_{\text {cone }}} \dot{Q}_{\text {cone }}^{\prime \prime \prime} d V=\int_{0}^{2 \pi} \int_{0}^{r(\xi)} \int_{0}^{S} \dot{Q}_{\text {cone }}^{\prime \prime \prime} d z \cdot r d r \cdot d \theta,
$$

$187 r(\xi)$ is schematically shown in Figure 4 (b) and varies from 0 to $R_{w}$ for $z$ in the interval of 0 to $S$. 188 By introducing $r(\xi)$ into equation (18) the bounds of the integral are defined

$$
\iiint_{V_{\text {cone }}} \dot{Q}_{\text {cone }}^{\prime \prime \prime} d V=\int_{0}^{2 \pi} \int_{0}^{\frac{Z \cdot R_{W}}{S}} \int_{0}^{S} \dot{Q}_{\text {cone }}^{\prime \prime \prime} d z \cdot r d r \cdot d \theta .
$$

189 And now by integration over $\theta, r$ and $z$, the net power produced with the conical-OPD heat source, 190 which will be a function of $H$ and $S$, can be determined

$$
2 \pi \int_{0}^{\frac{z \cdot R_{w}}{S}} \int_{0}^{S}\left[\frac{2 \alpha P_{w}}{H \pi R_{w}^{2}} e^{-\frac{2\left(r^{2}\right)}{R_{w}^{2}}} \cdot \xi\right] d z \cdot r d r=\alpha P_{w} .
$$

191 By integrating equation (20) and substituting the bounds of the integral, we obtain 


$$
\frac{\alpha \cdot S \cdot P_{w}}{H}\left[\frac{\xi^{2}}{2}+\frac{1}{4} e^{-2 \xi^{2}}\right]_{0}^{1}=\alpha P_{w},
$$

192 and by inserting the upper and lower bounds, the following expression is obtained

$$
0.283834 \frac{\alpha . S \cdot P_{w}}{H}=\alpha \cdot P_{w}
$$

193 from which the following relation between $S$ and $H$ is determined:

$$
S \cong 3.52 H
$$

194 Having obtained this relationship between $S$ and $H$, it is sufficient to find one of them in order to 195 adjust the shape of the predicted melt pool profile to that of the experiments. In this study, the $S$ 196 value is changed and used as an independent variable for finding and calibrating the shape of the 197 heat source.

\section{2.3. Computational Fluid Dynamics (CFD)}

199 As the laser heats up the powder layer and subsequently the underneath bulk material beyond their 200 melting points, the material becomes liquid and hence highly deformable. In the presence of the 201 concentrated heat source, extremely high temperature gradients will also form which will 202 consequently lead to thermally-induced shear stresses that cause the liquid to flow and circulate 203 within the melt pool.

204 To find the velocity field inside the melt pool it is necessary to solve the continuity and momentum 205 equations, respectively, see e.g. [51].

$$
\begin{aligned}
& \frac{\partial\left(\rho u_{i}\right)}{\partial x_{i}}=0 \\
& \begin{aligned}
\frac{\partial}{\partial t}\left(\rho u_{i}\right)+\frac{\partial}{\partial x_{j}} & \left(\rho u_{i} u_{j}\right) \\
& =-\frac{\partial p}{\partial x_{i}}+\frac{\partial}{\partial x_{j}}\left[\mu\left(\frac{\partial u_{i}}{\partial x_{j}}+\frac{\partial u_{j}}{\partial x_{i}}-\frac{2}{3} \delta_{i j} \frac{\partial u_{k}}{\partial x_{k}}\right)\right]-\frac{K_{C}\left(1-f_{l}\right)^{2}}{C_{K}+f_{l}^{3}} \cdot u_{i} \\
& -\rho g_{i} \beta\left(T-T_{l}\right)
\end{aligned}
\end{aligned}
$$

206
The divergence of the velocity field on the right hand side of equation (25) vanishes because of the incompressibility of the flow shown in equation (24). The derivative on the left hand side of the linear momentum balance equation is the total derivative in a Eulerian framework and the velocity field components are described by the vector $u_{i}\left(\mathrm{~m} \cdot \mathrm{s}^{-1}\right)$.

The third term in equation (25) is the solidification drag force where the terms $c\left(\mathrm{~kg} \cdot \mathrm{m}^{-3} \cdot \mathrm{s}^{-1}\right)$ and $B$ are Carman-Kozeny constants, which are numerically big and very small, respectively [52]-[55]. Based on equation (25), when the liquid fraction goes to zero and the material solidifies, the drag force will become a significant number. On the other hand, when the liquid fraction is one, the 
214 drag force will vanish. In the current study $c$ and $B$ are set to $4 \mathrm{e} 5\left(\mathrm{~kg} \cdot \mathrm{m}^{-3} \cdot \mathrm{s}^{-1}\right)$ and $1 \mathrm{e}-4$ respectively. 215 Furthermore, the last term in equation (25) expresses the force caused by the buoyancy effect

216 which in this work is modelled based on the Boussinesq approximation and $\beta\left(\mathrm{K}^{-1}\right)$ is the thermal 217 expansion coefficient in equation (25).

\section{CFD boundary conditions}

219 All of the boundaries are assumed to be no-slip walls except for the top boundary which is set to 220 a slip-wall condition, i.e.:

$$
\begin{array}{ll}
u_{i}=0 \quad, & \partial \Omega_{\text {sides }} \cup \partial \Omega_{\text {bottom }} \\
u_{i} \cdot n_{i}=0, & \partial \Omega_{\text {top }}
\end{array}
$$

221 Based on equation (27), only the z-direction of the velocity will become zero and the CFD 222 boundary conditions are shown in Figure 5.

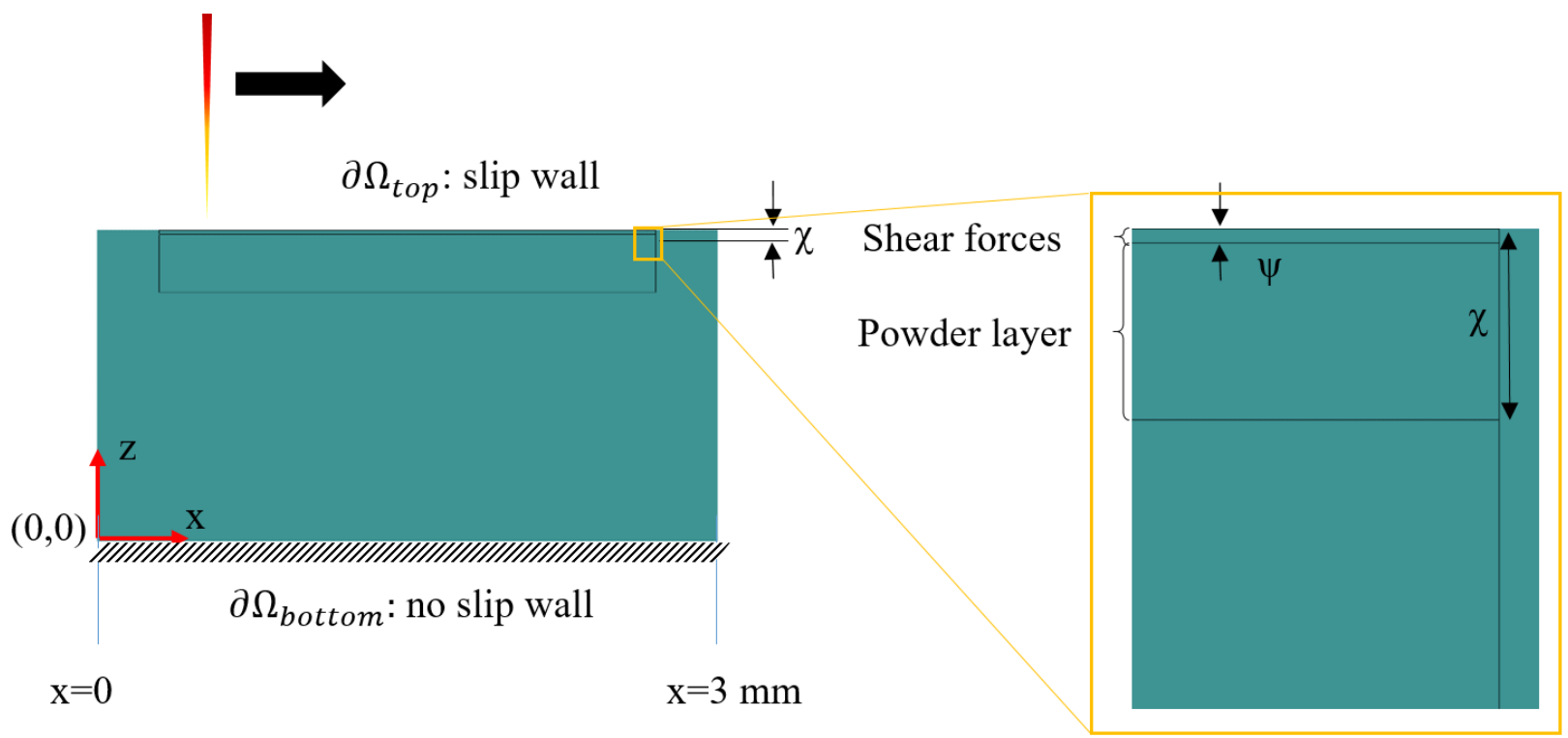

Figure 5. Boundary conditions for the CFD model. The top surface is assumed to be a slip-wall while all other faces are no slip walls. The domain in which the thermally-induced shear stresses are introduced has the depth $\psi$ and is set on the top of the whole domain.

227 The thermally-induced shear stresses are active as surface tractions on the top boundary and more 228 generally, wherever large thermal gradients prevail in the liquid, i.e.:

$$
\begin{array}{cc}
\boldsymbol{\sigma}_{x z}=-\gamma \frac{\partial T}{\partial x}, & \partial \Omega_{t o p} \\
\sigma_{y z}=-\gamma \frac{\partial T}{\partial y} & \quad \partial \Omega_{t o p}
\end{array}
$$

$229 \sigma_{x z}$ and $\sigma_{y z}(\mathrm{~Pa})$ are top surface shear stresses in the $\mathrm{x}$ and $\mathrm{y}$ directions. $\gamma\left(\mathrm{N} \cdot \mathrm{m}^{-1} \cdot \mathrm{K}^{-1}\right)$ is the linear 230 dependency of the surface tension on the temperature. From a numerical point of view, imposing 
231 both a slip wall condition along with shear stresses on the same boundary is unphysical and in this 232 regard an additional volumetric force has been introduced on a very thin subdomain (with 233 thickness $\psi$ ) beneath the top boundary, in such a way that it will produce an equal amount of shear 234 force close to that boundary, as shown in Figure 5.

$$
\begin{array}{cc}
\boldsymbol{F}_{\psi, \boldsymbol{x}}=-\frac{\gamma}{\psi} \frac{\partial T}{\partial x} \quad, \quad \Omega_{\psi} \\
\boldsymbol{F}_{\psi, \boldsymbol{y}}=-\frac{\gamma}{\psi} \frac{\partial T}{\partial y} \quad, \quad \Omega_{\psi}
\end{array}
$$

$235 \quad F_{\psi, x}$ and $F_{\psi, y}\left(\mathrm{~N}^{-\mathrm{m}^{-3}}\right)$ are volumetric forces related to the thermo-capillary effect that are imposed 236 inside the top subdomain $\Omega_{\psi}$. This a standard procedure for implementing the Marangoni effect in 237 CFD model [17].

\section{2.4. Metallurgical sub-model}

239 In order to study the metallurgical phenomena of the process, a metallurgical sub-model has been 240 developed and subsequently linked to the CFD model described earlier in sections 2.1. and 2.3.. 241 The methodology used to derive the important metallurgical indicators, are schematically shown 242 in Figure 6.

(a)

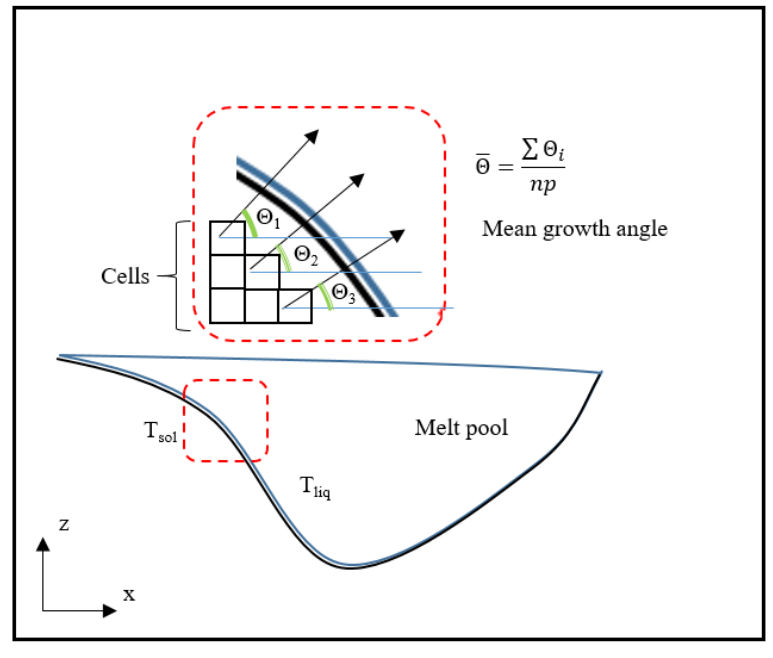

243

244

245

246

247

248

249 for the number of computational cells.

Figure 6. Schematics of the methodologies used to find (a) the growth direction and (b) metallurgical conditions. np in (a) stands

(b)

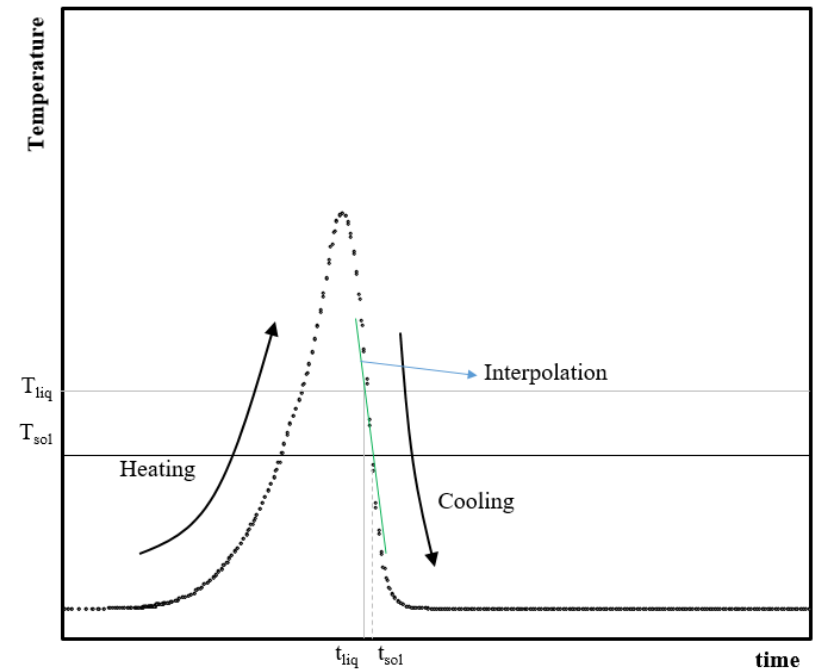

A schematic view of a cross-section of the melt pool profile, parallel to the laser track, is shown in Figure 6 (a). The black arrows show the temperature gradient vectors in the $\mathrm{x}-\mathrm{z}$ plane and as expected, they are perpendicular to the melt pool borders. The growth direction for each computational element is found via the following expression [40], [56] 


$$
\theta=\arctan \left(\frac{G_{z}}{G_{x}}\right)
$$

250 where $G_{z}$ and $G_{x}$ in equation (32) are the temperature gradients in z and x directions, respectively. 251 According to Figure 6 (a), the mean growth direction is the average value of the cells' growth 252 angles. In this way, first, the growth direction for every individual cell is calculated with equation

253 (32), then the mean growth direction is found via an averaging on all studied cells.

254 The cooling rate can be found via [32], [33]

$$
C r=\frac{T_{l i q}-T_{\text {sol }}}{t_{l i q}-t_{\text {sol }}},
$$

255 And $t_{l i q}$ and $t_{s o l}$, are the times for start and end of solidification. Due to very large cooling rates, a 256 linear interpolation is performed to find the times at which the temperature intersects the liquidus 257 and solidus lines, as shown in Figure 6 (b).

258 The solidification temperature gradient is found at the start of the solidification (at $t=t_{\text {liq }}$ ) [33].

259 The growth velocity $R\left(\mathrm{~m} . \mathrm{s}^{-1}\right)$ is, however, a dependent variable and is defined as [15], [16]

$$
R=\frac{C r}{G}
$$

260 There is another metallurgical condition, denoted the morphology factor which serves as an

261 indicator of the morphology of the grains, which is also a dependent variable e.g.

$$
F=\frac{G}{R}
$$

262 All of the four aforementioned metallurgical conditions along with the growth direction are 263 calculated based on the CFD model data and have been reported in the subsequent sections.

\section{3. Mesh sensitivity analysis and validation}

265 The current model has been numerically verified by means of mesh independency analysis and 266 experimentally validated by comparing the predicted melt pool with those found in experiments.

\section{Mesh independency}

268 The process parameters chosen for the mesh independency analysis are given in Table 2 . Five

269 different cases for the size and number of elements are selected. Based on Table 2, by increasing 270 the number of elements to about 2 million from 800,000, the average temperature of the domain 271 increased $0.04 \mathrm{~K}$ and the melt pool size became about $1 \%$ larger. Hence, in the current study we

272 use the case 3 configuration for the calculations henceforth in the paper, due to its sufficient 273 accuracy and lower required CPU time, compared to the cases 4 and 5. 
274 Table 2. Process parameters for all three different cases for mesh independency analysis along with the calculated average

275 domain temperature.

\begin{tabular}{|c|c|c|c|c|c|c|c|}
\hline \multirow[t]{2}{*}{ Case } & \multicolumn{4}{|c|}{ Process parameter } & \multirow{2}{*}{$\begin{array}{l}\text { Elements } \\
\text { count }\end{array}$} & \multirow{2}{*}{$\begin{array}{c}\text { Mean } \\
\text { temperature }(K)\end{array}$} & \multirow{2}{*}{$\begin{array}{l}\text { Melt pool volume } \\
\qquad\left(\times 10^{-14} \mathbf{m}^{3}\right)\end{array}$} \\
\hline & $\begin{array}{l}\text { Input } \\
\text { power }\end{array}$ & $\begin{array}{l}\text { Scan } \\
\text { speed }\end{array}$ & $\begin{array}{l}\text { Beam } \\
\text { radius }\end{array}$ & $\begin{array}{l}\text { Layer } \\
\text { thickness }\end{array}$ & & & \\
\hline & $\begin{array}{l}P_{w} \\
(\mathrm{~W})\end{array}$ & $\begin{array}{c}V_{w} \\
\left(\mathrm{~mm} \cdot \mathrm{s}^{-1}\right)\end{array}$ & $\begin{array}{c}R_{w} \\
(\mu \mathrm{m})\end{array}$ & $\begin{array}{c}\psi \\
(\mu \mathrm{m})\end{array}$ & & & \\
\hline 1 & & & & & 385398 & 402.95 & 43.6 \\
\hline 2 & & & & & 584736 & 403.16 & 50.1 \\
\hline 3 & 200 & 800 & 50 & 20 & 803966 & 403.17 & 50.8 \\
\hline 4 & & & & & 1151773 & 403.20 & 51.2 \\
\hline 5 & & & & & 1906215 & 403.21 & 51.4 \\
\hline
\end{tabular}

276 Moreover, the current model has been calibrated by varying the scanning speed and comparing the 277 size of the predicted melt pool with the ones measured experimentally [57]. The process 278 parameters used for this validation are given in Table 3.

Table 3. Process parameters for the validation [57]-[59].

\begin{tabular}{ccccc}
\hline Case & \multicolumn{4}{c}{ Process parameter } \\
\hline & $\begin{array}{c}\text { Input } \\
\text { power }\end{array}$ & $\begin{array}{c}\text { Scan } \\
\text { speed }\end{array}$ & $\begin{array}{c}\text { Beam } \\
\text { radius }\end{array}$ & $\begin{array}{c}\text { Layer } \\
\text { thickness }\end{array}$ \\
\cline { 2 - 4 } & $P_{w}$ & $V_{w}$ & $R_{w}$ & $\psi$ \\
& $(\mathrm{W})$ & $\left(\mathrm{mm} \cdot \mathrm{s}^{-1}\right)$ & $(\mu \mathrm{m})$ & $(\mu \mathrm{m})$ \\
A & & 200 & & \\
B & 200 & 300 & 50 & 20 \\
C & & 400 & & \\
\hline
\end{tabular}

280 The comparison between the numerically predicted and experimentally measured molten zones 281 for all three different cases gathered in Table 3, is shown in Figure 7. 

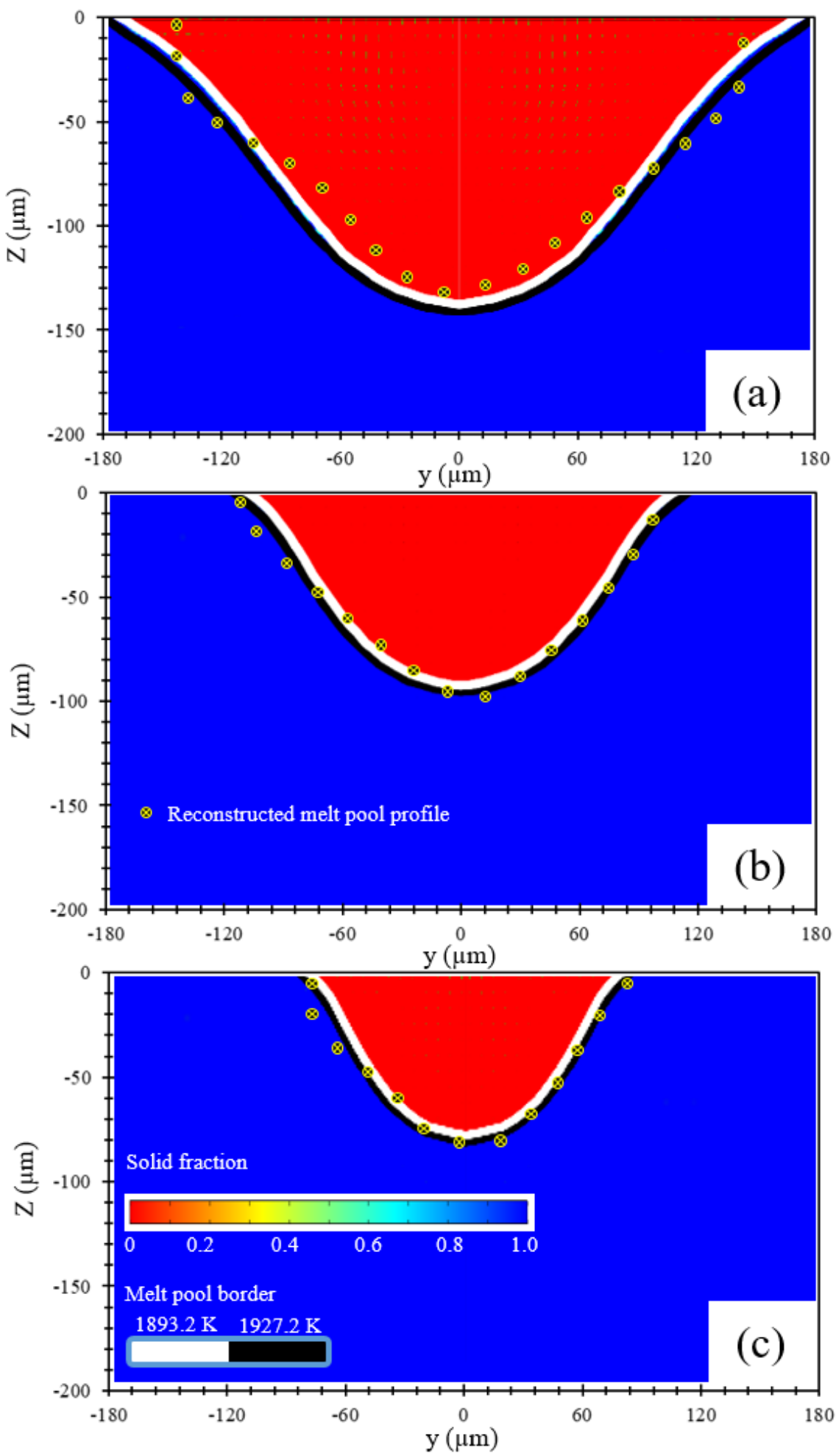

283 Figure 7. Comparison between predicted and experimentally measured shapes of the melt pool [57] for (a) V = 200 mm. $\mathrm{s}^{-1}$, (b) $\mathrm{V}$ $284=300 \mathrm{~mm} \cdot \mathrm{s}^{-1}$ and (c) $\mathrm{V}=400 \mathrm{~mm} \cdot \mathrm{s}^{-1}$. The red color shows the molten region while the blue stands for the solid zone. White and 285 black lines shown in the numerical contours respectively show the liquidus and solidus lines.

286 The reconstructed melt pool profiles which were measured experimentally are shown with markers 287 in Figure 7. According to Figure 7 (a), the predicted melt pool profile is slightly wider than the 
288 experimental one. The predicted depth of the melt pool is in an even better agreement with the 289 experiments, see Figure 7 (a). When the scanning speed is increased to $300 \mathrm{~mm} . \mathrm{s}^{-1}$, the melt pool 290 becomes smaller in both depth and width, as expected. This was also experimentally shown by 291 Wang et al. [60] for stainless steel. For $300 \mathrm{~mm} \cdot \mathrm{s}^{-1}$, shown in Figure 7 (b), the predicted melt pool 292 profile is in better agreement with the experimental one. According to Figure 7 (b), the predicted 293 width and depth of the melt pool in case B are $240 \mu \mathrm{m}$ and $100 \mu \mathrm{m}$ respectively, which matches 294 well with the reconstructed experimental micrographs. Moreover, it is observed that further 295 increase in travel speed leads to even smaller width and depth of the melt pool, which is due to 296 shorter contact time between laser and the material (see Figure 7 (c)). It is also visually seen in 297 Figure 7 that when the laser speed is increased from $200 \mathrm{~mm} \cdot \mathrm{s}^{-1}$ to $400 \mathrm{~mm} \cdot \mathrm{s}^{-1}$, the melt pool depth 298 is reduced from $140 \mu \mathrm{m}$ to less than $90 \mu \mathrm{m}$. The resulting melt pool shape based on the 299 conventional cylindrical OPD-based heat source (originally devised for pure conduction models

300 [47]) will have an unrealistically high width to depth ratio [48]-[50], unlike the proposed conico301 Gaussian heat source which can capture the shape of the melt pool more correctly.

\section{$302 \quad 4 . \quad$ Results and discussions}

\section{Thermal behavior}

304 The temperature profile along with the calculated velocity field are shown for four different times 305 in Figure 8. The corresponding laser input power, scanning speed and beam radius are respectively $306200 \mathrm{~W}, 300 \mathrm{~mm} \cdot \mathrm{s}^{-1}$ and $90 \mu \mathrm{m}$. 

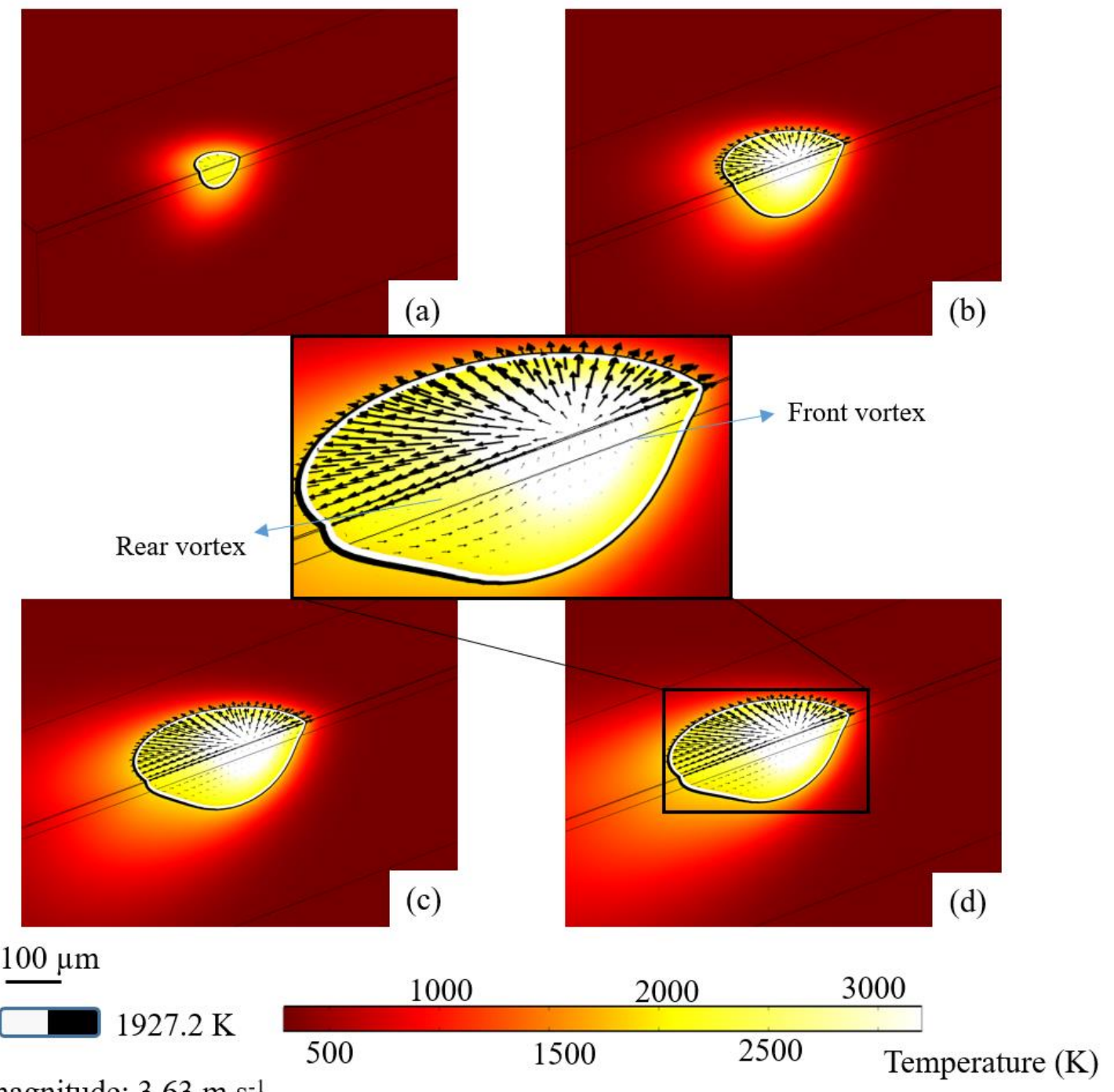

Velocity magnitude: $3.63 \mathrm{~m} . \mathrm{s}^{-1}$

308 Figure 8. Temperature contour for four different instants in time (calculated from when the laser starts moving): (a) $0.1 \mathrm{~ms}$, (b) 0.4 $309 \mathrm{~ms}$, (c) $1.2 \mathrm{~ms}$ and (d) $2.0 \mathrm{~ms}$. The melting lines are shown in black and white colors. Note the progressive transition of the shape 310 of the melt pool from symmetrical to elongated in the $\mathrm{x}$-direction.

311 Based on Figure 8 (a) and (b), the melt pool at the onset of the process grows equally to the sides, 312 while becoming also deeper towards the bulk material. As time passes further, the melt pool 313 obtains its final egg-shaped morphology, according to Figure 8 (c) and will keep it for the rest of 314 the process. The velocity field on the top surface shown in Figure 8 is radially outward and due to 315 incompressibility of the liquid zone, two vortices are spotted on front and back of the melt pool. 316 The relative size of these two vortices are highly dependent on the process parameters and will be 317 discussed later. 


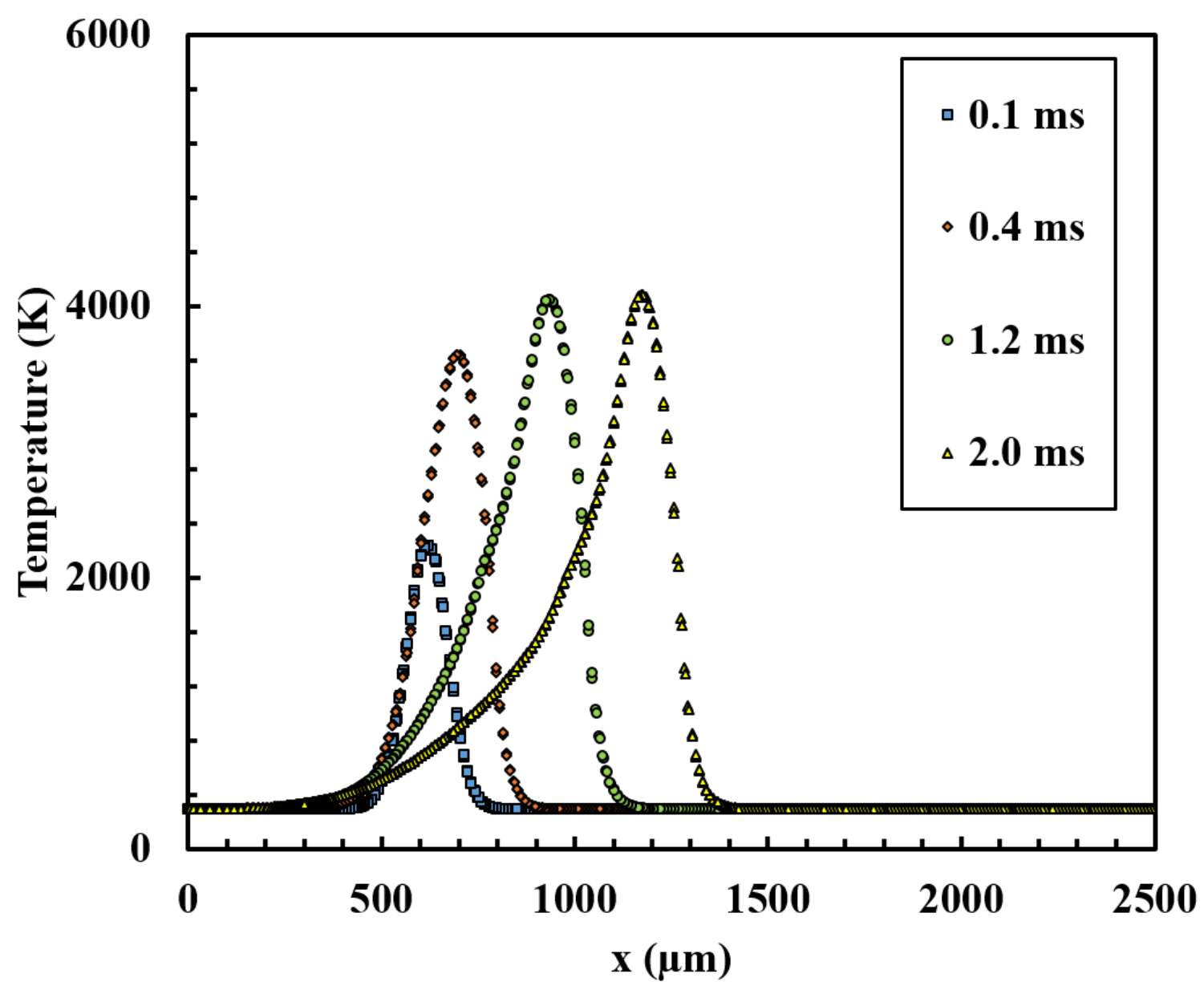

Figure 9. T-x profile measured at the scanning line at four different times. Note that the maximum temperature reaches a stable condition from which it remains constant throughout the rest of the process.

321 What is also interesting is that, not only the shape of the melt pool will not change after $1 \mathrm{~ms}$, but 322 also the peak temperature will remain the same after $1 \mathrm{~ms}$, according to Figure 9. In other words, 323 the process becomes stable from this point on and this relaxation or stabilization time might vary 324 depending on the imposed boundary conditions or input parameters.

325 To further investigate the effect of laser speed and beam size on this stabilization time, the peak 326 temperature is plotted against time for different processing conditions in Figure 10. 
(a)

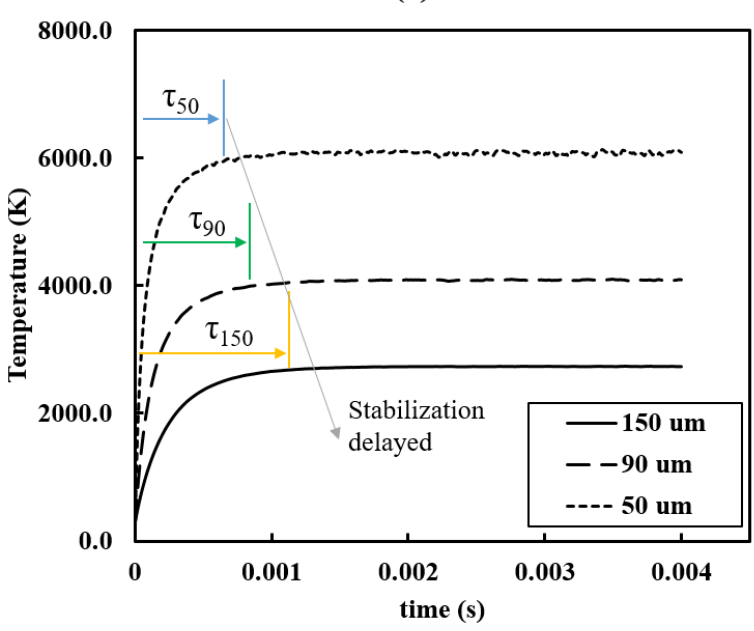

(b)

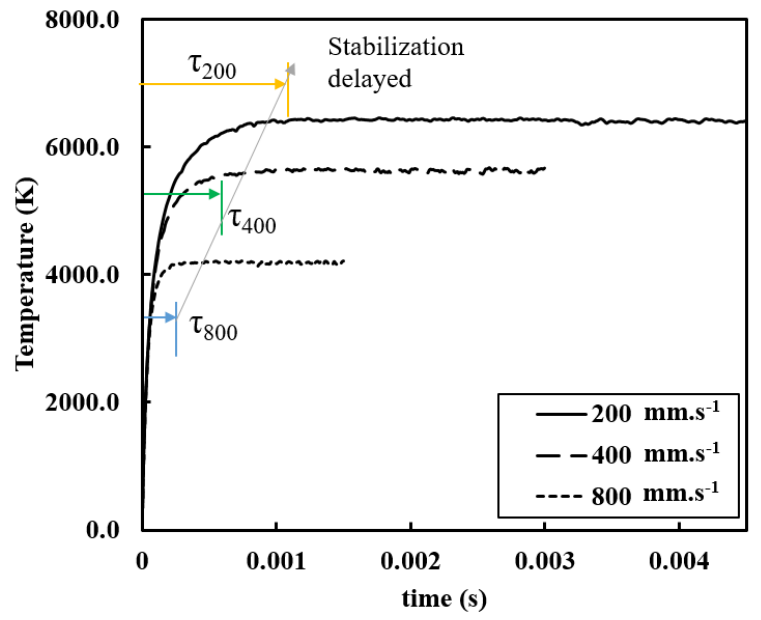

Figure 10. Plot of peak temperature against time for (a) varying beam size $\left(\mathrm{v}=300 \mathrm{~mm} \cdot \mathrm{s}^{-1}\right)$ and $(\mathrm{b})$ varying scanning speeds $(\mathrm{R}=$ $50 \mu \mathrm{m})$. The laser power is set to $200 \mathrm{~W}$.

330 According to Figure 10 (a) when the beam size is increased, lower peak temperatures are obtained, 331 which is because of a lower and more uniform distribution of laser heat flux over the beam area. 332 It is also noticed that choosing bigger beam sizes lead to a delay in the peak temperature profiles 333 shown in Figure 10 (a). The same trend is observed for varying scanning speeds where lower laser 334 travel speeds will cause a delay in stabilization of the process, since a bigger melt pool is formed 335 due to longer laser-material interaction, hence more time is required to reach the stable condition, 336 see Figure 10 (b),.

\section{Melt pool evolution and dimensionless analysis}

338 The volume of the melt pool versus time has been plotted in Figure 11 (a) where it is well observed 339 that like the peak temperature which reaches a stable condition after some time, shown in Figure 34011 (b), the melt pool size will also converge to a specific value as well. The same trend is moreover 341 seen in Figure 11 (c) where the maximum velocity magnitude also approaches a stable level after 342 some time from the onset of the process. 

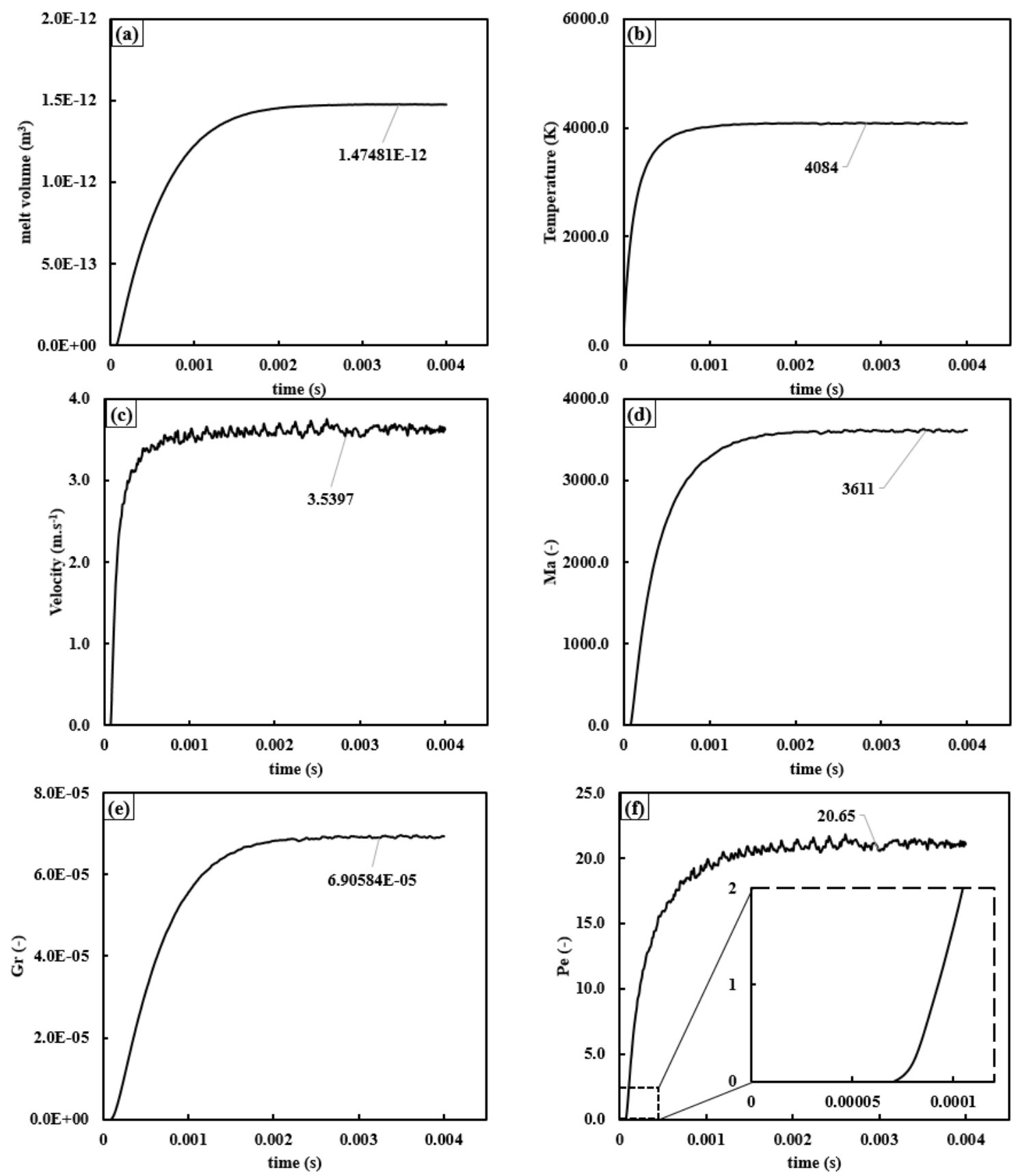

344 Figure 11. (a) Melt pool volume, (b) peak temperature, (c) maximum velocity magnitude, (d) Marangoni number, (e) Grashof 345 number and (f) Peclet number versus time. The input laser power and travel speed are $200 \mathrm{~W}$ and $300 \mathrm{~mm} . \mathrm{s}^{-1}$. The beam radius is 346 set to be $90 \mu \mathrm{m}$.

347 To understand the effect of the thermally-induced shear stresses on the fluid flow, the Marangoni 348 number is used

$$
M a=\frac{\rho L_{M} \Delta T_{\max }|\gamma|}{\mu^{2}}
$$


354

\section{5}

356

357

358

359

360

361

362

363

364

365

\section{6}

367

368

369

370

371

372

373

374

375

which is a dimensionless number expressing the relative strength of thermally-induced shear stresses to the viscous stresses in a liquid. $L_{M}(\mathrm{~m})$ is the characteristic length of the melt pool which is assumed to be one-eighth of the apparent melt pool radius [20]. Apparent melt pool radius is in turn the radius of a hemisphere with the same volume as the melt pool. $\Delta T_{\max }(\mathrm{K})$ is the difference between the solidus and peak temperature.

Moreover, Grashof's number is used to study the effect of the buoyancy force on the fluid flow

$$
G r=\frac{\rho^{2} \beta g L_{B}^{3} \Delta T_{\max }}{\mu^{2}} .
$$

Grashof's number scales the relative strength of the buoyancy forces to the viscous forces. A low order of magnitude of Grashof's number $(\mathrm{O}(\mathrm{Gr})<1)$ means that the buoyancy forces have an insignificant effect on the fluid flow motion, while a higher order of magnitude implies the opposite.

According to Figure 11 (d) and (e), while the Marangoni number reaches a significant value of 3611 , the Grashof number converges to a negligible number of $6.9 \mathrm{e}-5$. This comparison reveals that the buoyancy effect has a minimal impact on the fluid dynamics inside the melt pool, compared to the viscous forces. On the other hand, a much bigger order of magnitude of the Marangoni number means that the thermally-induced shear forces outweigh the viscous forces in the melt region, meaning that the melt flow is mostly driven by the thermo-capillary effect. Finally, in order to study the dominant mode of heat transfer, the Peclet number is applied [16]

$$
P e=\frac{\rho C_{P} U L_{M}}{k} .
$$

A Peclet number smaller than one indicates conduction as the dominant mode of heat transfer whereas a value greater than one, indicates convection being more dominant. According to Figure 11 (f), the Peclet number, except for the very beginning of the process, will be considerably greater than one and within 1 millisecond it reaches the value of 20.65 which underlines the dominant role of fluid flow in the transfer of heat in the melt pool. As will be shown in the next section, the dominance of convection in heat transfer will highly govern melt pool size and its peak temperature, which will consequently affect the predicted metallurgical conditions as well.

To further understand the importance of the convective heat transfer, or in other words, the impact of neglecting the fluid flow inside the melt pool, a simplified model without the fluid flow and hence only considering conductive heat transfer was developed. 
(a)

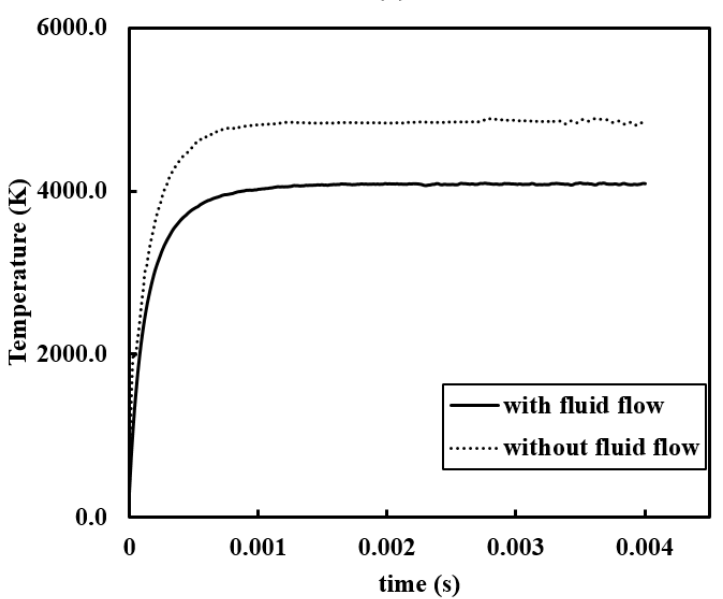

(b)

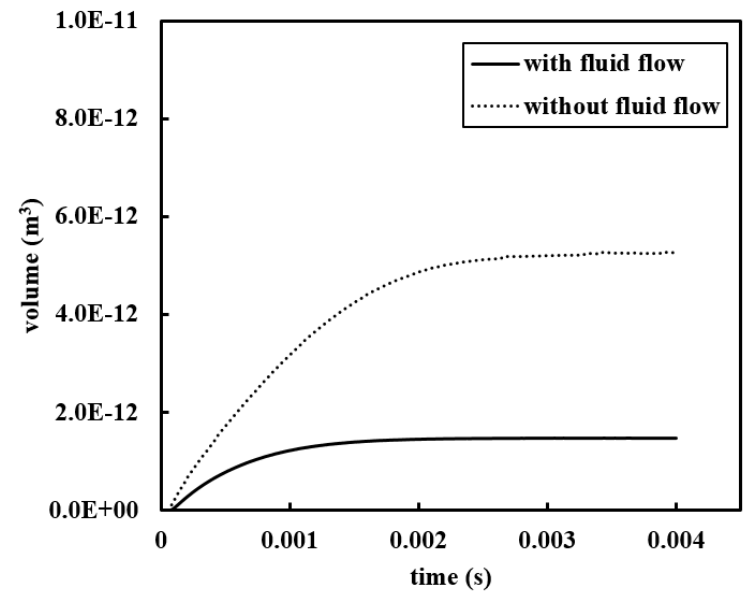

Figure 12. Plot of (a) peak temperature and (b) melt pool volume versus time. The dashed lines are the results of the pure conduction model without the fluid flow. Beam radius $90 \mu \mathrm{m}$, laser speed $300 \mathrm{~mm} \cdot \mathrm{s}^{-1}$ and power set to $200 \mathrm{~W}$.

As seen in Figure 12 (a), neglecting the fluid flow will result in higher maximum temperatures and it will also dramatically affect the melt pool size and its geometry as well, see Figure 12 (b). More specifically, the numerical results show that neglecting the fluid flow inside the melt pool will lead to an almost $+20 \%$ higher peak temperatures as well as a 3-4 times bigger melt region, based on Figure 12.

The main reason that the peak temperature and also the melt pool size are lower in the case with inclusion of the fluid flow is not surprisingly that, the fluid flow will highly increase the rate of heat transfer between the melt pool borders and the colder bulk material.

(a)

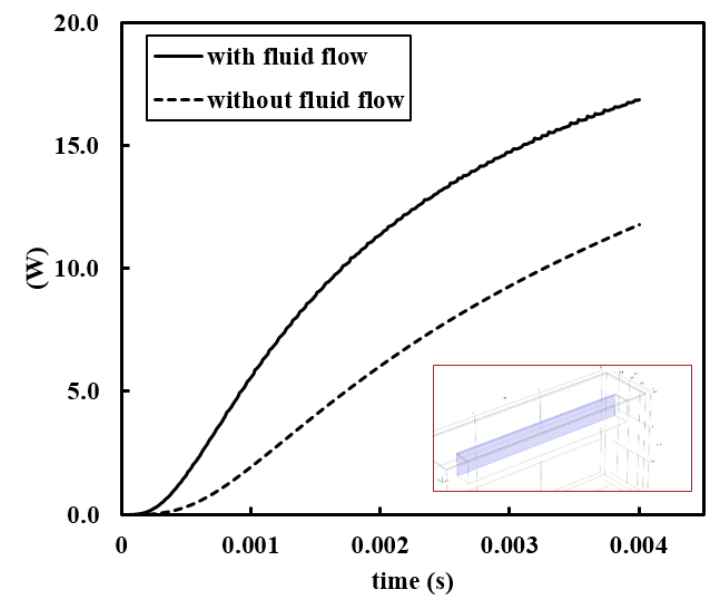

(b)

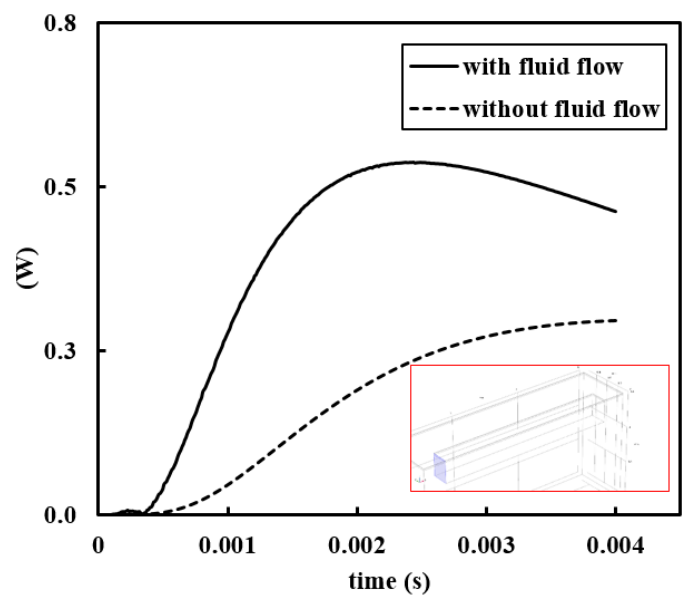

Figure 13. The net outwards power calculated on (a) a plane at $y=0.225 \mathrm{~mm}$ (at the left side of the melt pool) and (b) a plane at $\mathrm{x}=0.3 \mathrm{~mm}$ (at the back of the melt pool), versus time. Dashed lines stand for pure conduction calculations and continuous lines belong to the thermo-fluid model. The planes of which the net output power is calculated, are shown with blue color in the red boxes.

In order to analyze this phenomenon, the rate of heat transfer towards the colder bulk material through the melt pool borders has been calculated on two planes adjutant to the laser track, see Figure 13. According to Figure 13 (a), the net output power predicted by the thermo-fluid model 
395 reaches $16 \mathrm{~W}$ within 3 milliseconds while for the pure conduction model this value would be 396 around $10 \mathrm{~W}$, which is one-third lower. The same trend is also observed on the y-z plane at the 397 back of the melt pool, according to Figure 13 (b). Hence, the inclusion of fluid flow inside the melt 398 pool will highly increase the rate of heat transfer which will ultimately lead to lower peak 399 temperatures and smaller melt pool sizes.

\section{Parametric study}

401 A parametric study has been performed to separately investigate the effect of the laser beam radius 402 and its travel speed on shape and size of the melt pool and its peak temperature. The process 403 parameters for the parametric study are given in Table 4. Two different cases have been analyzed 404 here, one group with varying beam radius and another group with varying scanning speeds, 405 denoted the R-group and V-group, respectively.

406 Table 4. Process parameters and case ids for the parametric study.

\begin{tabular}{|c|c|c|c|c|c|}
\hline \multirow[t]{2}{*}{ group } & \multirow[t]{2}{*}{ Case id } & \multicolumn{4}{|c|}{ Process parameter } \\
\hline & & Power (W) & $\begin{array}{l}\text { Scan speed } \\
\left(\mathrm{mm} \cdot \mathrm{s}^{-1}\right)\end{array}$ & $\begin{array}{c}\text { Beam } \\
\text { radius }(\mu \mathrm{m})\end{array}$ & $\begin{array}{c}\text { Layer } \\
\text { thickness }(\mu \mathrm{m})\end{array}$ \\
\hline \multirow{3}{*}{ 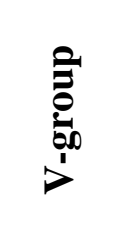 } & V200 & & 200 & & \\
\hline & V400 & 200 & 400 & 50 & 20 \\
\hline & V800 & & 800 & & \\
\hline \multirow{3}{*}{ 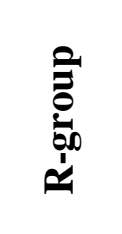 } & R50 & & & 50 & \\
\hline & R90 & 200 & 300 & 90 & 20 \\
\hline & $\mathrm{R} 150$ & & & 150 & \\
\hline
\end{tabular}

407 The stable melt pool temperature contour and velocity fields are shown for all six different cases 408 in Figure 14 (a)-(f) and at the end of each process. 

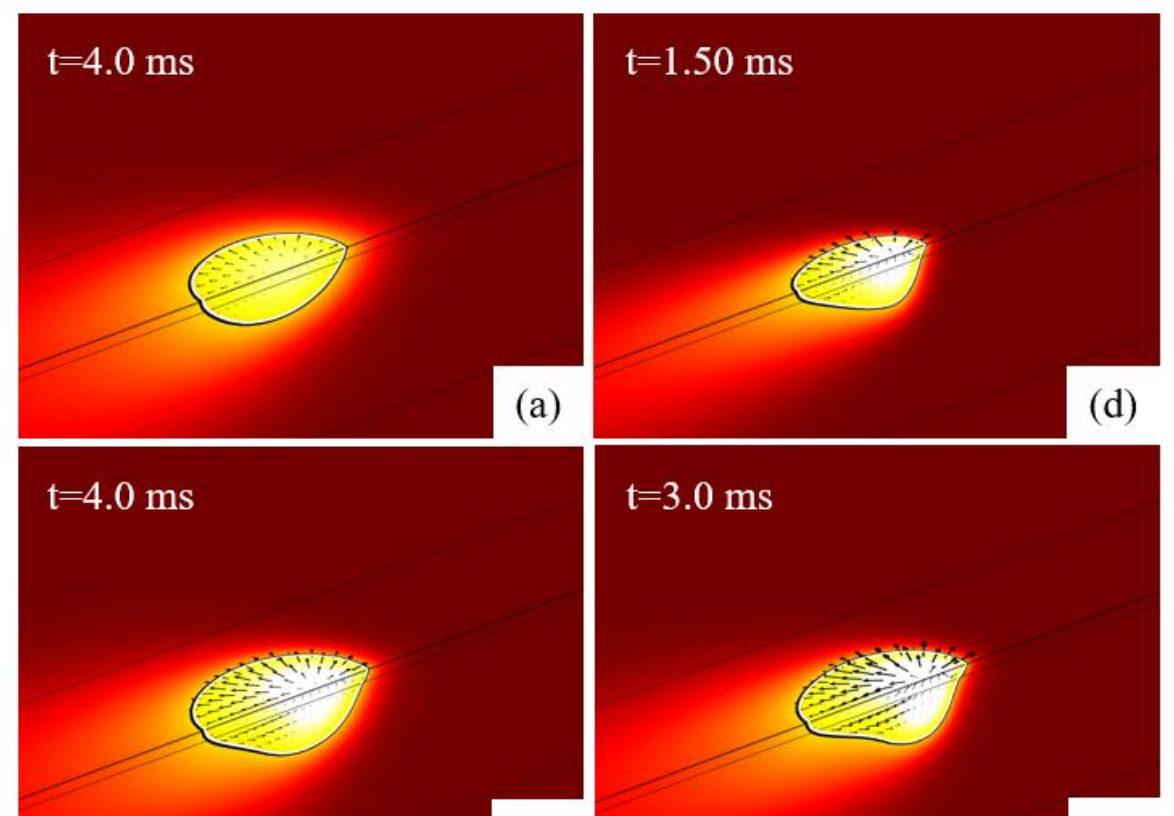

(b)

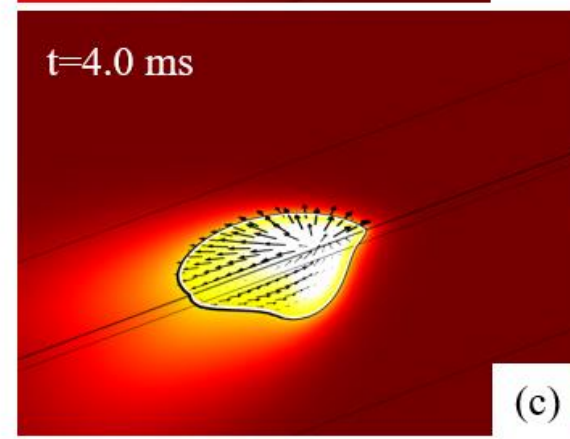

(e)

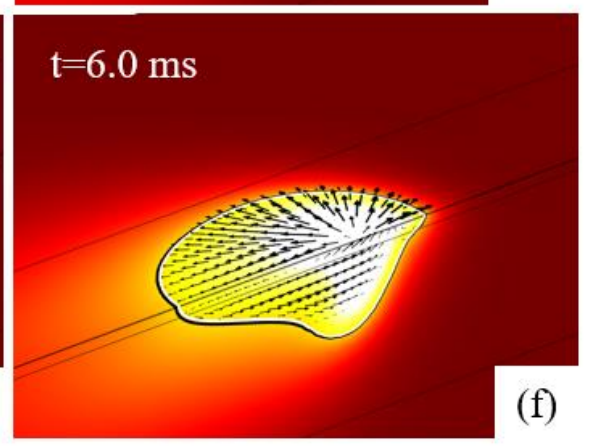

$\leftrightarrow 100 \mu \mathrm{m}$

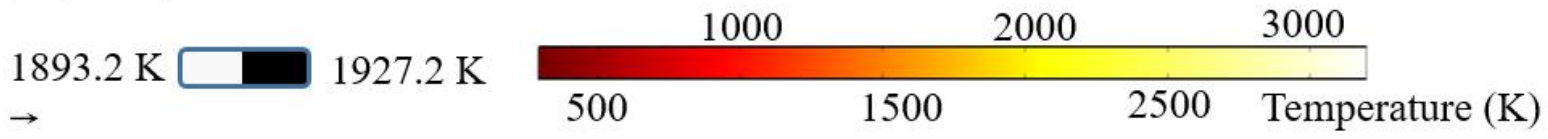

Velocity magnitude: 5.13 m.s.

410 Figure 14. Temperature contour and velocity field along with the melt pool borders shown for case: (a) R150, (b) R90, (c) R50, (d)

411 V800, (e) V400 and (f) V200, at the end of the process. Note that for larger beam sizes, the melt pool will have a more uniform

412 shape.

$\mathbf{4 1 3}$ It is clearly seen in Figure 14 (a)-(c) that increasing the laser beam radius will lower the peak 414 temperature and the overall molten zone. Furthermore, it is revealed that by reducing the size of 415 the laser beam radius from $150 \mu \mathrm{m}$ to $90 \mu \mathrm{m}$ and finally $50 \mu \mathrm{m}$, the melt pool's geometry becomes 416 more asymmetric, while the speed is kept constant. The reason behind this transformation can be $\mathbf{4 1 7}$ attributed to the fact that for case R150, the heat flux has lower peak values and is more uniformly 418 distributed.

419 It is also seen from Figure 14 (a)-(c) that for smaller beam sizes, because of the existence of larger 420 temperature gradients, the maximum velocity magnitude will be higher as well, which is directly 
linked to formation of elevated thermally-induced shear stresses in the fluid. On the other hand, increasing the laser travel speed will result in a more asymmetrical melt pool, with shorter tails, according to Figure 14 (d)-(f). For further analysis regarding the melt pool size, peak temperature and opposing forces, relevant quantities have been calculated and presented in Table 5.

Table 5. Data regarding melt pool information and the corresponding dimensionless numbers for the parametric study.

\begin{tabular}{|c|c|c|c|c|c|c|c|c|c|}
\hline \multirow[t]{2}{*}{ Case id } & \multicolumn{5}{|c|}{ Melt pool data } & \multicolumn{4}{|c|}{ Dimensionless numbers } \\
\hline & $\begin{array}{l}\text { Volume } \\
\qquad\left(\mathrm{m}^{3}\right)\end{array}$ & $\begin{array}{c}\text { Peak } \\
\text { Temp. } \\
(\mathrm{K}) \\
\end{array}$ & $\begin{array}{c}\text { Max. } \\
\text { Velocity } \\
\left(\mathrm{m} \cdot \mathrm{s}^{-1}\right)\end{array}$ & $\begin{array}{l}\text { Vorticity } \\
\qquad\left(\mathrm{s}^{-1}\right)\end{array}$ & $\operatorname{Gr}(-)$ & Ma (-) & $\operatorname{Pe}(-)$ & $\operatorname{Ar}(-)$ & Ec (-) \\
\hline V200 & 2.2E-12 & 6388.9 & 5.1 & 2174.0 & $2.1 \mathrm{e}-04$ & 8414.7 & 33.9 & $2.4 \mathrm{e}-09$ & $7.7 \mathrm{e}-06$ \\
\hline V400 & $1.1 \mathrm{E}-12$ & 5672.1 & 4.9 & 768.2 & $9.3 e-05$ & 5710.0 & 26.3 & $1.7 \mathrm{e}-09$ & $8.5 \mathrm{e}-06$ \\
\hline V800 & $5.1 \mathrm{E}-13$ & 4220.5 & 4.1 & 308.2 & $2.5 \mathrm{e}-05$ & 2676.5 & 16.7 & $1.2 \mathrm{e}-09$ & $9.6 \mathrm{e}-06$ \\
\hline $\mathrm{R} 50$ & $1.5 \mathrm{E}-12$ & 6091.9 & 5.3 & 1033.6 & $1.4 \mathrm{e}-04$ & 6966.5 & 31.1 & $1.8 \mathrm{e}-09$ & $8.8 \mathrm{e}-06$ \\
\hline R90 & $1.5 \mathrm{E}-12$ & 4091.7 & 3.6 & 661.8 & $6.9 \mathrm{e}-05$ & 3610.3 & 21.1 & $2.0 \mathrm{e}-09$ & $7.9 \mathrm{e}-06$ \\
\hline $\mathrm{R} 150$ & $9.8 \mathrm{E}-13$ & 2730.5 & 2.0 & 282.3 & $1.8 \mathrm{e}-05$ & 1200.0 & 10.0 & $2.3 e-09$ & $6.1 \mathrm{e}-06$ \\
\hline
\end{tabular}

426

It can be seen that lower travel speeds will lead to higher peak temperatures and bigger melt pools and one can say that there is a linear relation between the inverse travel speed and the melt pool size, which goes well in hand with the classical effect of linear heat input [27]. On the other hand, an increase in beam size will lead to a sharp decrease in the peak temperature. Moreover, from the table, it is evident that the Marangoni number is directly linked with the input parameters and that a reduction in beam size and travel speed will lead to bigger thermally-induced shear forces, which will directly impact the mode of heat transfer, via changing the fluid flow patterns. Accordingly, the associated Peclet number will also rise, as either the beam size or travel speed decreases, hence resulting in a more pronounced convective heat transfer. On the other hand, the role of the buoyancy forces are very negligible in both heat and fluid flows, which is seen from low levels of the Grashof's number given in Table 5. However, it is the Archimedes number $\left(G r \cdot R^{-2}\right)$ that decides the relative importance of free convection (due to buoyancy) to forced convection (due to thermally-induced shear stresses). This number, according to Table 5 is very negligible, so the dominant mode of convection heat transfer is the forced convection. Furthermore, to study the relative weight of kinetic energy to the internal energy, the Eckert number is calculated (defined as $V^{2} \cdot C_{P}^{-1} \cdot \Delta T^{-1}$ ) and given in Table 5. As expected, it is observed that by reducing the travel speed, the Eckert number goes down as well. Moreover, according to the table, bigger beam sizes lead to lower Eckert numbers, which is also expected, since lower speed levels are found. Finally, the calculated average vorticity inside the melt pool is also provided in Table 5 and accordingly lower beam size and travel speed will lead to stronger circulations and vortices, which is directly linked to higher thermally-induced shear forces. 
The melt pool profile in the $\mathrm{x}-\mathrm{z}$ plane, including the liquid fraction contour, solidus and liquidus lines, velocity vectors, stream lines and more importantly, the vectors of direction of dendrite growth for all six mentioned cases are illustrated in Figure 15.

(a)

(d)

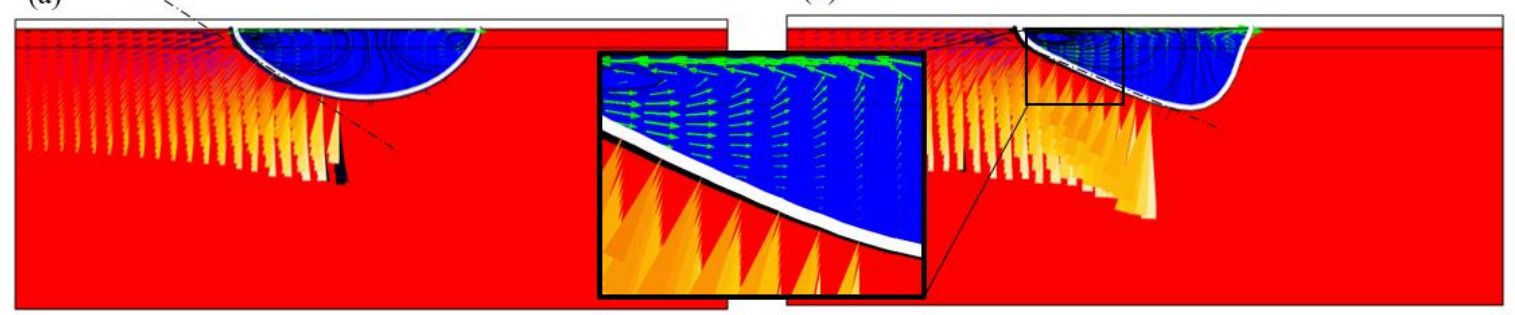

(b)

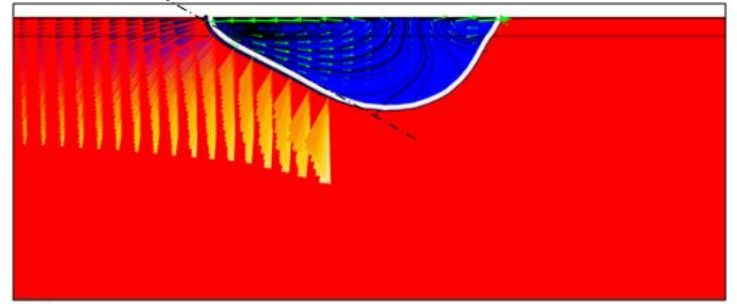

(c)

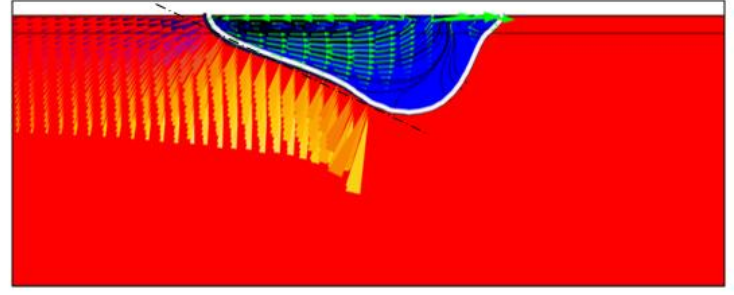

$1893.2 \mathrm{~K}$ (e)

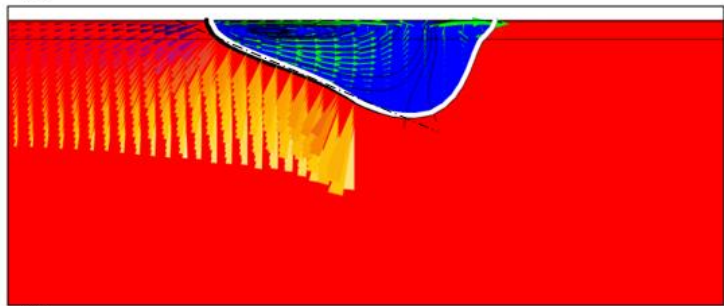

(f)

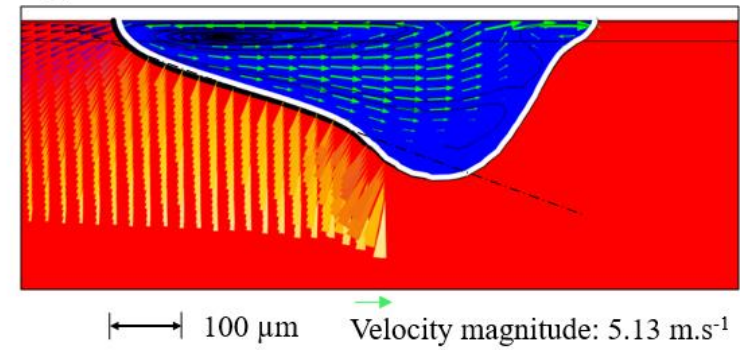

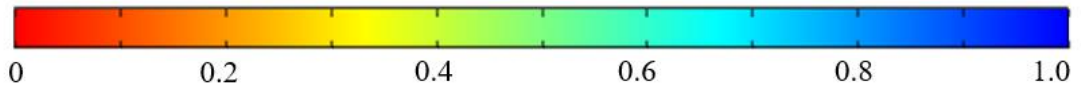

Liquid fraction (-)

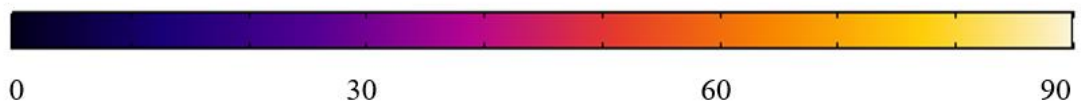

Dendrite growth angle (deg)

Figure 15. Contour of liquid fraction and vectors of plane velocity field along with the vectors of direction of dendritic growth (shown with cones) for case: (a) R150, (b) R90, (c) R50, (d) V800, (e) V400 and (f) V200 after reaching their corresponding stabilization times. Note the formation of the two vortices on the front and back of the melt pool.

454 Several interesting informations regarding the fluid dynamics and microstructure can be deduced 455 from Figure 15. It is clearly seen in Figure 15 (a)-(c) that by increasing the size of the laser beam 456 radius, the melt pool becomes more symmetric. According to Figure 15 (a), for a relatively large 457 beam radius, the melt pool profile becomes elliptical in the x-z plane and two almost equally-sized 458 vortices are formed on the front and back of the melt pool. However, by reducing the beam size, 459 hence imposing higher heat fluxes on the domain, the front vortex gets much smaller with higher $460 \mathrm{x}$-direction velocities while the rear circulation expands dramatically. Furthermore, based on 461 Figure 15 (d)-(f), by reducing the scanning speed of the laser, the size of the melt pool increases 462 in all directions. 
The effect of process parameters on the dendritic growth directions is interesting as well. It is very well established in the literature that the dendrites grow parallel to the solidification temperature gradient [56]. The colored cones shown in Figure 15 represent the direction of the dendritic growth, which is parallel to the heat flow direction [61], and it is seen that these lines are all perpendicular to the tail of the melt pool (see blowup for clarification). It is moreover observed from Figure 15 (a)-(c) that reducing the size of the laser beam, the mean dendritic growth direction angle with respect to the horizontal plane decreases. Moreover, based on Figure 15 (d)-(f), the reduction in scanning speed results in a more horizontal tail of the melt pool (is quantified later on in Table 6) which will consequently lead to lower angles of dendritic growth as well.

The solidification parameters, including cooling rate, morphology factor, temperature gradient and solidification growth speed are calculated by means of a microstructural sub-model described in section 2.4. The solidification temperature gradient and solidification growth velocity are plotted against time for a cross-section of the melt pool in a $y-z$ plane, at $x=1.4 \mathrm{~mm}$, in Figure 16 (a). Each point in Figure 16 corresponds to a solidified finite element node in the model in the noted crosssection.

(a)

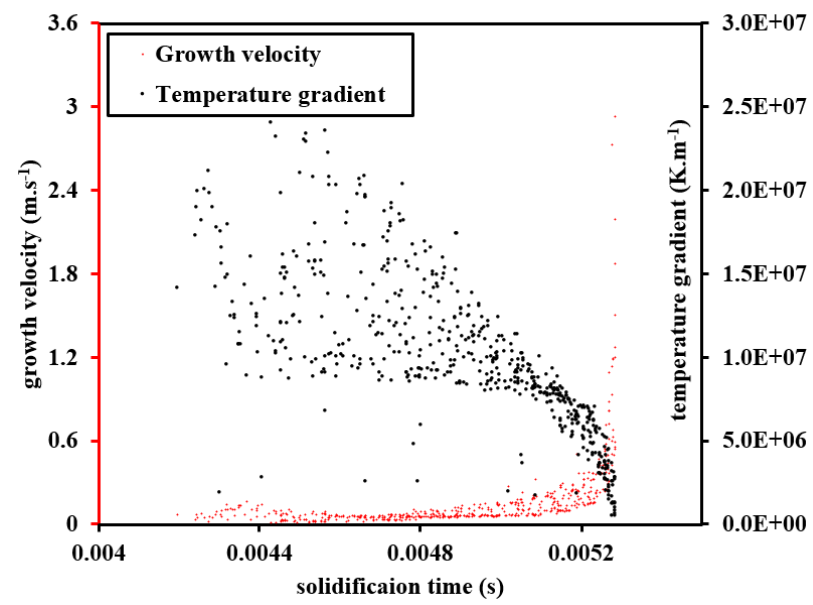

(b)

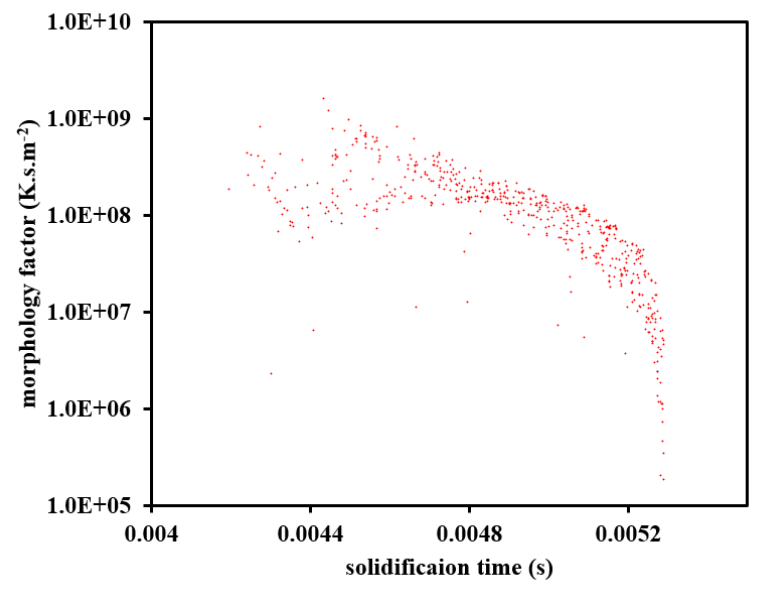

Figure 16. (a) Solidification growth velocity and temperature gradient versus time and (b) the plot of calculated morphology factor against time. The calculation is carried out on a $y-z$ plane perpendicular to the laser path at $x=1.4 \mathrm{~mm}$ for V200 case.

According to Figure 16 (a), the solidification growth velocity increases steadily with time and it is observed that at the end of solidification, the growth velocity rises dramatically to a significant amount of $3 \mathrm{~m} . \mathrm{s}^{-1}$. The underlying reason for this sudden increase can be explained by the fact that at the final phase of the solidification, the ratio of the melt pool total area to its remaining volume will be very big. The area-volume ratio is also an indicator of the cooling capability to the remaining energy inside the melt pool due to the latent heat of fusion. In this regard, at the end of the solidification, the solidification speed grows dramatically. Moreover, based on Figure 16 (a), the temperature gradient experiences a different trend compared to that of the growth velocity and decreases during the course of the solidification process. It is noteworthy to mention that the same trend is observed for both solidification thermal gradient and growth speed, for the EBM process of metals as well [33]. The morphology factor which is defined as the ratio of the solidification thermal gradient to the solidification growth speed is determined for the mentioned cross-section 
and has been plotted against time in Figure 16 (b) and it is well observed that the morphology factor decreases during the solidification process continuously. A lower morphology factor is an indicator of dominant equiaxed microstructure while higher levels stand for columnar morphology [17]. Typically the columnar microstructures lead to an unwanted anisotropy in mechanical properties of the parts which require an additional post-process (heat treatment) to remove it [62].

The contours of the mentioned solidification temperature gradient and growth speed are shown in Figure 17 (a) and (b), respectively.

(a)

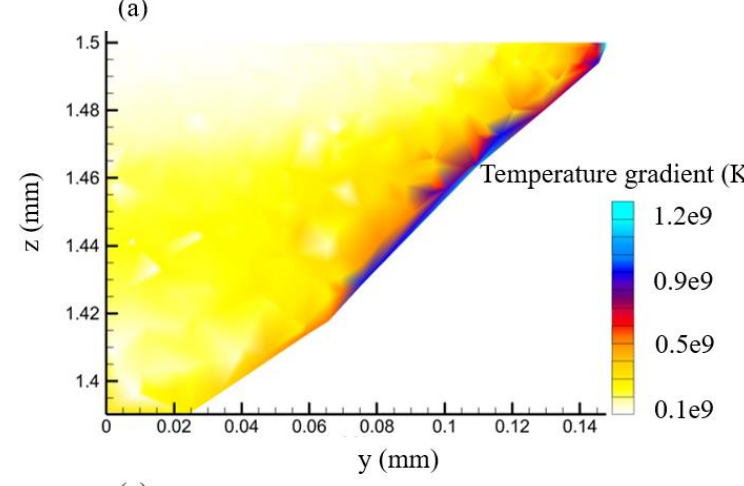

(c)

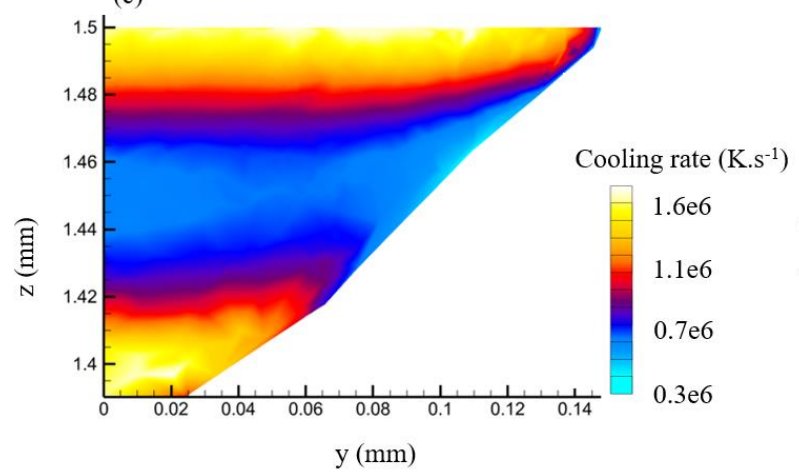

(b)

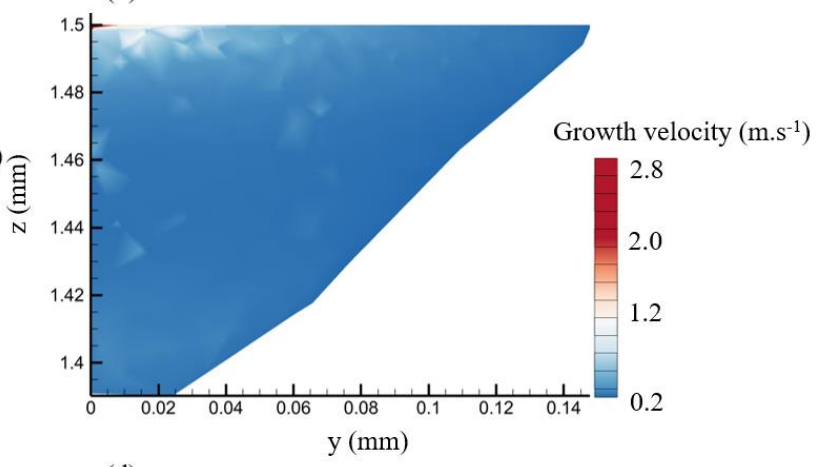

(d)

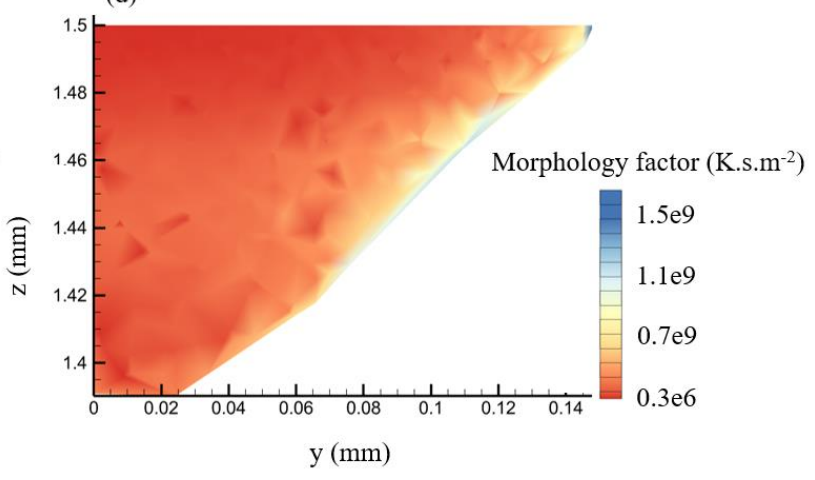

500

501

502

503

504

505

506

507

508

509

510

511

512

513

514

515

516

Figure 17. Contours of: (a) solidification temperature gradient, (b) growth speed, (c) cooling rate and (d) morphology factor at a y$\mathrm{z}$ cross-section at $\mathrm{x}=1.4 \mathrm{~mm}$ at $\mathrm{t}=6 \mathrm{~ms}$ for V200 case. Due to the symmetry only half of the data are shown.

Based on Figure 17 (a), the maximum value of the solidification temperature gradient is found on the initial melt pool borders and it decreases steadily as the melt pool front moves upwards. The solidification growth speed is observed to be highest on the top of the melt pool and in the center line, based on Figure 17 (b), where both findings are consistent with numerical results of the laser welding process as well [17]. The contour of the cooling rate is shown in Figure 17 (c), where the cooling rate is highest at the top and bottom of the initial melt pool's borders and has its lowest values in the middle of the centerline. The cooling rate is a good indicator for the size of the grains or dendrites forming during solidification where lower cooling rates lead to bigger grain or dendrite sizes [15], [16]. Thijs et al. [63] reported that the microstructure at the bottom of the melt pool is much finer than the one found in the internal region, which is in accordance with the cooling rate contour shown in Figure 17 (c). On the other hand, the morphology factor is a tool to study the morphology of the grains formed. In general, a decrease in the morphology factor results in formation of columnar and even equiaxed grains. In Figure 17 (d), the contour of the morphology factor is shown at the cross-section. The maximum value of the morphology factor occurs at the 
$\mathbf{5 1 7}$ borders of the melt pool and lowest on the center line, leading to higher probability of formation 518 of equiaxed grains on this line and at the final phase of the solidification, which is also seen for 519 laser welding [17], [64]. The calculated mean solidification parameters for all the six different 520 cases are given in Table 6. The values for the solidification thermal gradient and growth velocity 521 are in the same order as the ones reported for another L-PBF process in the literature [40]. 522 According to this table, the cooling rate and solidification growth velocity, both increase with $\mathbf{5 2 3}$ increasing laser travel speed, leading to smaller grains. The same observation was also reported 524 for laser welding and EBM [17], [58]. One the other hand, the morphology factor drops as the 525 scanning speed goes up, hence increasing the probability of formation of more equiaxed grains. 526 Also, the calculated dendrite direction angle, with respect to the horizon, will increase by $\mathbf{5 2 7}$ increasing the beam size. In this way, one can manipulate the direction, size and morphology of 528 the dendrites formed during the L-PBF process, by changing the process parameters such as travel 529 speed and beam size.

530 Table 6. Average value of the calculated solidification parameters.

\begin{tabular}{lccccc}
\hline Case id & \multicolumn{5}{c}{ Solidification parameters } \\
\hline & $\mathrm{C}\left(\mathrm{K} . \mathrm{s}^{-1}\right)$ & $\mathrm{G}\left(\mathrm{K} . \mathrm{m}^{-1}\right)$ & $\mathrm{F}\left(\mathrm{K} . \mathrm{s} . \mathrm{m}^{-2}\right)$ & $\mathrm{R}\left(\mathrm{m} . \mathrm{s}^{-1}\right)$ & $\Theta(\mathrm{deg})$ \\
& Cooling rate & $\begin{array}{c}\text { Temperature } \\
\text { gradient }\end{array}$ & $\begin{array}{c}\text { Morphology } \\
\text { factor }\end{array}$ & $\begin{array}{c}\text { Growth } \\
\text { velocity }\end{array}$ & $\begin{array}{c}\text { Dendritic } \\
\text { direction angle }\end{array}$ \\
\cline { 2 - 6 } V200 & $1.05 \mathrm{E}+06$ & $1.00 \mathrm{E}+07$ & $1.52 \mathrm{E}+08$ & 0.174 & 19.97 \\
V400 & $2.02 \mathrm{E}+06$ & $1.23 \mathrm{E}+07$ & $1.00 \mathrm{E}+08$ & 0.249 & 23.06 \\
V800 & $4.59 \mathrm{E}+06$ & $1.60 \mathrm{E}+07$ & $7.69 \mathrm{E}+07$ & 0.399 & 22.75 \\
R50 & $1.53 \mathrm{E}+06$ & $1.14 \mathrm{E}+07$ & $1.25 \mathrm{E}+08$ & 0.237 & 25.51 \\
R90 & $1.56 \mathrm{E}+06$ & $1.02 \mathrm{E}+07$ & $9.97 \mathrm{E}+07$ & 0.238 & 29.25 \\
$\mathrm{R} 150$ & $1.46 \mathrm{E}+06$ & $7.84 \mathrm{E}+06$ & $6.34 \mathrm{E}+07$ & 0.302 & 32.87 \\
\hline
\end{tabular}

531 Furthermore, to investigate the morphology of the grains formed during the mentioned process, a 532 plot of temperature gradient versus solidification growth speed has been made for varying scan 533 speeds in Figure 18 (a) and varying beam sizes in Figure 18 (b). 
(a)

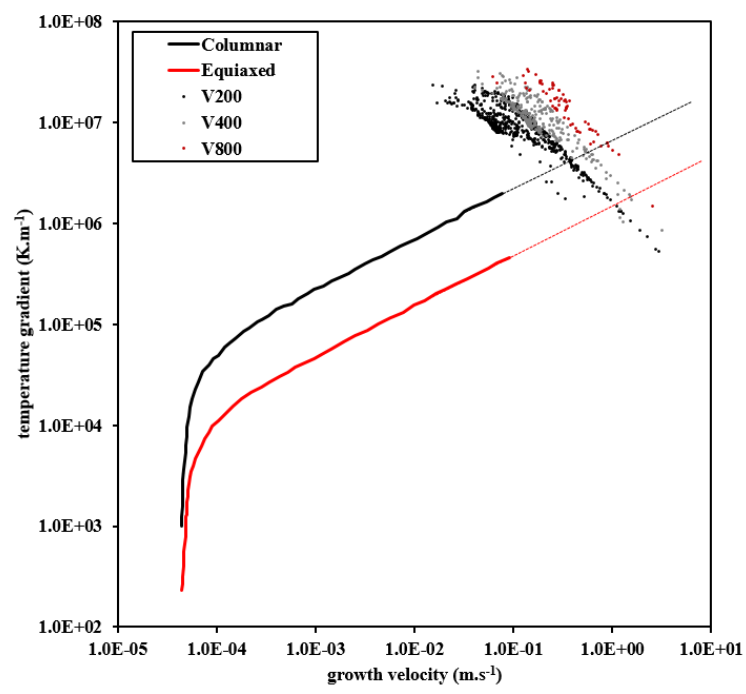

(b)

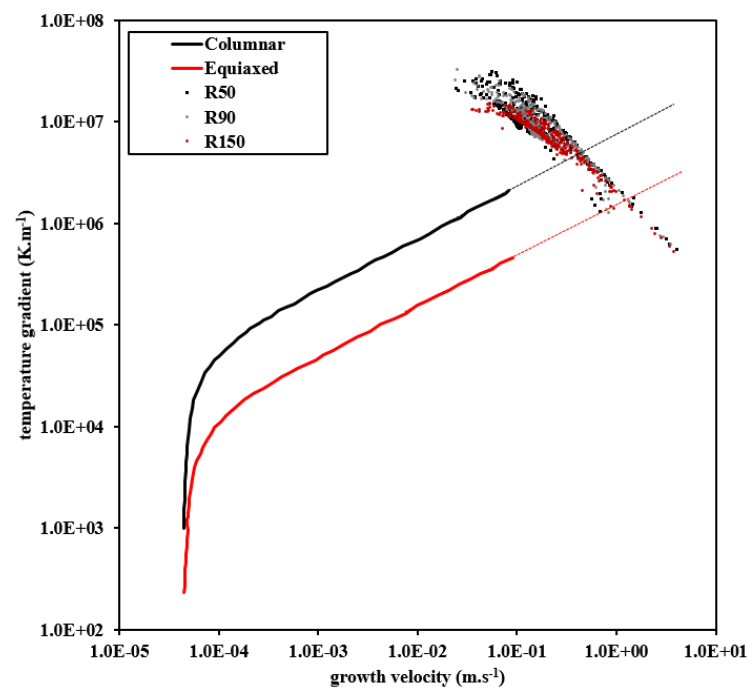

534

535

536

537

538

539

540

541

542

543

544

545

546

547

548

549

550

551

552

553

554

555

556

Figure 18. G-R map for varying (a) scan speed and (b) beam size. The red and black lines respectively show the approximate borders of the equiaxed and columnar regions for Ti6Al4V. Above the black line it is purely columnar, whereas below the red line it is purely equiaxed. The dashed lines stand for extrapolated data. The map is based on the data found in [32].

According to Figure 18 (a) and (b), most of the solidified region lies in the columnar zone, which is in agreement with experimental findings for L-PBF [62]. It is also observed that the morphology of the solidified zones moves towards the equiaxed zone at the end of the solidification where low thermal gradients along with high growth speeds are predicted, according to Figure 18 (a). Interestingly, a similar trend is observed for the EBM process, where at the end of the process, lower thermal gradients and higher growth speeds are obtained [32], [33]. This is also in agreement with the decrease in the morphology factor during the course of the solidification noted earlier. Overall, one can conclude from Figure 18 (a) that higher scanning speeds lead to higher thermal gradients and growth speeds, while the effect of changing beam size on the final solidification morphology is much lower as compared to varying the travel speed and in this way the morphology of the samples are much more sensitive to scanning speed than to beam size.

On the other hand, based on Table 6 and Figure 18 (a), higher laser beam speeds will cause higher solidification cooling rates. In this context, it should be mentioned that Zhang et al. introduced a simple expression that relates the cooling rate to the laser beam speed for the L-PBF process [65]

$$
\operatorname{Cr}\left(K . \mathrm{s}^{-1}, \mathrm{~mm} . \mathrm{s}^{-1}\right)=\left(2.07 \times 10^{4}\right) V_{\text {beam }}^{1.2}
$$

Where $V_{\text {beam }}\left(\mathrm{mm} \cdot \mathrm{s}^{-1}\right)$ in the above expression is the laser beam speed and according to this equation, higher cooling rates are obtained for higher scanning speeds, which shows the same trend as the results given in Table 6. Also, another simple equation which relates the grain sizes to the solidification cooling rate, based on a rapid solidification assumption, has been suggested by Broderick et al. [66]

$$
d(\mu m)=\left(3.1 \times 10^{6}\right) \operatorname{Cr}\left(K . s^{-1}\right)^{-0.93 \pm 0.1}
$$


Based on this, higher cooling rates will cause smaller grain sizes and based on what was mentioned earlier, one can obtain smaller grain sizes by simply choosing higher laser speeds. Furthermore, the tensile strength of the material is highly dependent on the grain sizes of the domain. As indicated by the following Hall-Petch-like empirical correlation [67]

$$
Y(M P a)=802.66+\frac{1236.5}{d(\mu m)^{0.5}},
$$

561

562

563

564

565

566

567

568

569

\section{0}

571

572

573

574

575

576

577

578

579

580

581

582

583

584

585

586

587

588

589

590

591

592

which relates Ti6Al4V's tensile strength, denoted $Y(\mathrm{MPa})$, to the average beta grain size $d$. According to equation (41) finer grain sizes will lead to higher tensile strength. Thus, one can improve a part's mechanical strength by simply increasing the laser beam speed, which causes the formation of finer grains during the solidification process. However, according to both Figure 18 and Table 6, changing the laser beam will not have a similar significant effect on the cooling rate, hence it influences the mechanical strength and grain morphology to a lesser extent. Moreover, it should be noted that the dominant grain morphology is still columnar for all cases studied and accordingly mechanical anisotropy is inevitable, which necessitates a post-process such as heat treatment to remove it.

\section{Conclusion}

In this work, a numerical model based on the FEM framework has been developed in COMSOL Multiphysics to study the heat and fluid flow along with metallurgical conditions during the LPBF process of the Ti6Al4V alloy. A systematic investigation regarding the impact of neglecting fluid flow inside the melt pool on the heat flow and melt pool dimensions is presented, alongside with a thorough analysis in terms of relevant dimensionless numbers. Also, a novel conicoGaussian heat source is developed to model the thermal interaction between the part and the laser, which relies on the concept of optical penetration depth (OPD). An analytical expression is derived which can be used to adjust the shape and geometry of the melt pool for validation. Furthermore, the model is both numerically verified through mesh independency analysis and validated with experimental results. The results show that neglecting the fluid flow will result in overestimated temperature fields and unrealistically large melt pools. Also the results show that the dominant mode of heat transfer is convection, as the Peclet number is significantly larger than one. Moreover, it is shown that the role of the buoyancy effect on heat and fluid flow is negligible compared to the much more pronounced effect of the thermally-induced shear forces. A parametric study is carried out in the second part of the paper to study the effect of varying beam size and travel speed on melt pool shape, solidification pattern and size and morphology of the grains. To study the metallurgical conditions, a microstructural sub-model is developed and coupled to the CFD model. It is observed that at the end of the solidification process, the morphology tends to become more equiaxed, compared to the onset of the process where it is fully columnar. Also, it is found that by choosing different process parameters, one can manipulate the direction of the dendrites' growth. Specifically, it is found that the overall effect of changing beam size on grain morphology is less pronounced than changing the travelling speed. 
Acknowledgments

594 This work has received funding from the European Union Horizon 2020 Marie Skłodowska_Curie

595 ITN PAM^2 project under grant agreement number 721383.

596 References

597 [1] J. Milewski, Additive manufacturing of metals. Springer series in materials science, vol 8, 2017.

599 [2] ASTM, Standard terminology for additive manufacturing technologies. ASTM Int 2013;

[3] T. DebRoy et al., "Additive manufacturing of metallic components - Process, structure

[4] S. R. A. Bhavar V, Kattire P, Patil V, Khot S, Gujar K, "review on powder bed fusion technology of metal additive manufacturing," in 4th International conference and exhibition on additive manufacturing technologies, 2014, pp. 1-2.

[5] K. S. Jamshidinia M, Sadek A, Wang W, "Additive manufacturing of steel alloys using laser powder-bed fusion," Adv Mater Process, vol. 173, no. 1, pp. 4-20, 2015.

[6] C. Kamath, B. El-Dasher, G. F. Gallegos, W. E. King, and A. Sisto, "Density of additively-manufactured, 316L SS parts using laser powder-bed fusion at powers up to 400 W," Int. J. Adv. Manuf. Technol., vol. 74, no. 1-4, pp. 65-78, 2014.

[7] N. T. Aboulkhair, N. M. Everitt, I. Ashcroft, and C. Tuck, "Reducing porosity in AlSi10Mg parts processed by selective laser melting," Addit. Manuf., vol. 1, pp. 77-86, 2014.

[8] H. Gong, K. Rafi, H. Gu, T. Starr, and B. Stucker, "Analysis of defect generation in Ti-6Al-4V parts made using powder bed fusion additive manufacturing processes," Addit. Manuf., vol. 1, pp. 87-98, 2014.

[9] T. Qi, H. Zhu, H. Zhang, J. Yin, L. Ke, and X. Zeng, "Selective laser melting of Al7050 powder: Melting mode transition and comparison of the characteristics between the keyhole and conduction mode," Mater. Des., vol. 135, pp. 257-266, 2017.

[10] M. J. Matthews, G. Guss, S. A. Khairallah, A. M. Rubenchik, P. J. Depond, and W. E. King, "Denudation of metal powder layers in laser powder bed fusion processes," Acta Mater., vol. 114, pp. 33-42, 2016.

[11] J. Metelkova, Y. Kinds, K. Kempen, C. de Formanoir, A. Witvrouw, and B. Van Hooreweder, "On the influence of laser defocusing in Selective Laser Melting of 316L," Addit. Manuf., vol. 23, no. August, pp. 161-169, 2018.

[12] K. Antony, N. Arivazhagan, and K. Senthilkumaran, "Numerical and experimental investigations on laser melting of stainless steel 316L metal powders," $J$. Manuf. Process., vol. 16, no. 3, pp. 345-355, 2014.

[13] A. H. Faraji, M. Goodarzi, S. H. Seyedein, G. Barbieri, and C. Maletta, "Numerical modeling of heat transfer and fluid flow in hybrid laser-TIG welding of aluminum alloy AA6082," Int. J. Adv. Manuf. Technol., vol. 77, no. 9-12, pp. 2067-2082, 2015. 
[14] A. Hozoorbakhsh, M. I. S. Ismail, A. A. D. M. Sarhan, A. Bahadoran, and N. B. A. Aziz, "An investigation of heat transfer and fluid flow on laser micro-welding upon the thin stainless steel sheet (SUS304) using computational fluid dynamics (CFD)," Int. Commun. Heat Mass Transf., vol. 75, pp. 328-340, 2016.

[15] Z. Gan, H. Liu, S. Li, X. He, and G. Yu, "Modeling of thermal behavior and mass transport in multi-layer laser additive manufacturing of Ni-based alloy on cast iron," Int. J. Heat Mass Transf., vol. 111, pp. 709-722, 2017.

[16] Z. Gan, G. Yu, X. He, and S. Li, "Numerical simulation of thermal behavior and multicomponent mass transfer in direct laser deposition of Co-base alloy on steel," Int. J. Heat Mass Transf., vol. 104, pp. 28-38, 2017.

[17] W. Tan and Y. C. Shin, "Multi-scale modeling of solidification and microstructure development in laser keyhole welding process for austenitic stainless steel," Comput. Mater. Sci., vol. 98, pp. 446-458, 2015.

[18] W. Tan, N. S. Bailey, and Y. C. Shin, "Investigation of keyhole plume and molten pool based on a three-dimensional dynamic model with sharp interface formulation," $J$. Phys. D. Appl. Phys., vol. 46, no. 5, 2013.

[19] R. Rai, J. W. Elmer, T. A. Palmer, and T. Debroy, "Heat transfer and fluid flow during keyhole mode laser welding of tantalum, Ti-6Al-4V, 304L stainless steel and vanadium," J. Phys. D. Appl. Phys., vol. 40, no. 18, pp. 5753-5766, 2007.

[20] X. He, P. W. Fuerschbach, and T. DebRoy, "Heat transfer and fluid flow during laser spot welding of 304 stainless steel," J. Phys. D. Appl. Phys., vol. 36, no. 12, pp. 13881398, 2003.

[21] H. C. Tran and Y. L. Lo, "Heat transfer simulations of selective laser melting process based on volumetric heat source with powder size consideration," J. Mater. Process. Technol., vol. 255, no. May 2017, pp. 411-425, 2018.

[22] C. Qiu, C. Panwisawas, M. Ward, H. C. Basoalto, J. W. Brooks, and M. M. Attallah, "On the role of melt flow into the surface structure and porosity development during selective laser melting," Acta Mater., vol. 96, pp. 72-79, 2015.

[23] T. Heeling, M. Cloots, and K. Wegener, "Melt pool simulation for the evaluation of process parameters in selective laser melting," Addit. Manuf., vol. 14, pp. 116-125, 2017.

[24] L. E. Criales, Y. M. Arısoy, and T. Özel, "Sensitivity analysis of material and process parameters in finite element modeling of selective laser melting of Inconel 625," Int. J. Adv. Manuf. Technol., vol. 86, no. 9-12, pp. 2653-2666, 2016.

[25] Y. Huang, L. J. Yang, X. Z. Du, and Y. P. Yang, "Finite element analysis of thermal behavior of metal powder during selective laser melting," Int. J. Therm. Sci., vol. 104, pp. 146-157, 2016.

[26] L. E. Loh et al., "Numerical investigation and an effective modelling on the Selective Laser Melting (SLM) process with aluminium alloy 6061," Int. J. Heat Mass Transf., vol. 80, pp. 288-300, 2015.

[27] Q. Shi, D. Gu, M. Xia, S. Cao, and T. Rong, "Effects of laser processing parameters on 
thermal behavior and melting/solidification mechanism during selective laser melting of TiC/Inconel 718 composites," Opt. Laser Technol., vol. 84, pp. 9-22, 2016.

[28] S. Mohanty and J. Hattel, "Cellular scanning strategy for selective laser melting: Capturing thermal trends with a low-fidelity, pseudo-analytical model," Math. Probl. Eng., vol. 2014, no. June, 2014.

[29] S. Mohanty and J. H. Hattel, "Numerical model based reliability estimation of selective laser melting process," Phys. Procedia, vol. 56, pp. 379-389, 2014.

[30] Y. Liu, J. Zhang, and Z. Pang, "Numerical and experimental investigation into the subsequent thermal cycling during selective laser melting of multi-layer 316L stainless steel," Opt. Laser Technol., vol. 98, pp. 23-32, 2018.

[31] M. Bayat, S. Mohanty, and J. Hattel, "Numerical modelling and parametric study of grain morphology and resultant mechanical properties from selective laser melting process of Ti6AI4V," in eu spen 's 18 th International Conference \&, 2018, vol. 1, no. June.

[32] S. Bontha, N. W. Klingbeil, P. A. Kobryn, and H. L. Fraser, "Effects of process variables and size-scale on solidification microstructure in beam-based fabrication of bulky 3D structures," Mater. Sci. Eng. A, vol. 513-514, no. C, pp. 311-318, 2009.

[33] N. Raghavan et al., "Acta Materialia Numerical modeling of heat-transfer and the in fl uence of process parameters on tailoring the grain morphology of IN718 in electron beam additive manufacturing *," Acta Mater., vol. 112, pp. 303-314, 2016.

[34] P. Nie, O. A. Ojo, and Z. Li, "Numerical modeling of microstructure evolution during laser additive manufacturing of a nickel-based superalloy," Acta Mater., vol. 77, pp. 85-95, 2014.

[35] Y. C. Wu et al., "Numerical modeling of melt-pool behavior in selective laser melting with random powder distribution and experimental validation," J. Mater. Process. Technol., vol. 254, no. July 2017, pp. 72-78, 2018.

[36] S. A. Khairallah and A. Anderson, "Journal of Materials Processing Technology Mesoscopic simulation model of selective laser melting of stainless steel powder," $J$. Mater. Process. Tech., vol. 214, no. 11, pp. 2627-2636, 2014.

[37] S. A. Khairallah, A. T. Anderson, A. Rubenchik, and W. E. King, "Laser powder-bed fusion additive manufacturing: Physics of complex melt flow and formation mechanisms of pores, spatter, and denudation zones," Acta Mater., vol. 108, pp. 36-45, 2016.

[38] W. Yan et al., "Meso-scale modeling of multiple-layer fabrication process in Selective Electron Beam Melting: Inter-layer/track voids formation," Mater. Des., vol. 141, pp. 210-219, 2018.

[39] K. H. Leitz et al., "Fundamental analysis of the influence of powder characteristics in Selective Laser Melting of molybdenum based on a multi-physical simulation model," Int. J. Refract. Met. Hard Mater., vol. 72, no. October 2017, pp. 1-8, 2018.

[40] Y. S. Lee and W. Zhang, "Modeling of heat transfer, fluid flow and solidification microstructure of nickel-base superalloy fabricated by laser powder bed fusion," 
Addit. Manuf., vol. 12, pp. 178-188, 2016.

[41] D. De Baere, M. Bayat, S. Mohanty, and J. Hattel, "Thermo-fluid-metallurgical modelling of the selective laser melting process chain," Procedia CIRP, vol. 74, pp. 8791, 2018.

[42] H. Hamdi, M. El Ganaoui, and B. Pateyron, "Thermal Effects on the Spreading and Solidification of a Micrometric Molten Particle Impacting onto a Rigid Substrate Thermal Effects on the Spreading and Solidification of a Micrometric Molten Particle Impacting onto a Rigid Substrate," no. January 2015, 2012.

[43] Y. Zhang, S. Matthews, A. T. T. Tran, and M. Hyland, "Effects of interfacial heat transfer, surface tension and contact angle on the formation of plasma-sprayed droplets through simulation study," Surf. Coatings Technol., vol. 307, pp. 807-816, 2016.

[44] F. P. Incropera, D. P. DeWitt, T. L. Bergman, and A. S. Lavine, "Introduction to heat transfer," John Wiley \& Sons., 2007, pp. 559-618.

[45] D. Q. Zhang, Q. Z. Cai, J. H. Liu, L. Zhang, and R. D. Li, "Select laser melting of WNi-Fe powders: Simulation and experimental study," Int. J. Adv. Manuf. Technol., vol. 51, no. 5-8, pp. 649-658, 2010.

[46] W. Yan et al., "Multi-physics modeling of single/multiple-track defect mechanisms in electron beam selective melting," Acta Mater., vol. 134, pp. 324-333, 2017.

[47] A. Foroozmehr, M. Badrossamay, E. Foroozmehr, and S. Golabi, "Finite Element Simulation of Selective Laser Melting process considering Optical Penetration Depth of laser in powder bed," Mater. Des., vol. 89, pp. 255-263, 2016.

[48] T. Mukherjee, H. L. Wei, A. De, and T. DebRoy, "Heat and fluid flow in additive manufacturing -Part I: Modeling of powder bed fusion," Comput. Mater. Sci., vol. 150, no. February, pp. 304-313, 2018.

[49] T. Mukherjee, H. L. Wei, A. De, and T. DebRoy, "Heat and fluid flow in additive manufacturing - Part II: Powder bed fusion of stainless steel, and titanium, nickel and aluminum base alloys," Comput. Mater. Sci., vol. 150, no. February, pp. 369-380, 2018.

[50] T. Mukherjee and T. DebRoy, "Mitigation of lack of fusion defects in powder bed fusion additive manufacturing," J. Manuf. Process., vol. 36, no. October, pp. 442-449, 2018.

[51] W. M. H.K. Versteeg, "An-introduction-to-computational-fluid-dynamics." .

[52] S. F. Hosseinizadeh, A. A. Rabienataj Darzi, F. L. Tan, and J. M. Khodadadi, "Unconstrained melting inside a sphere," Int. J. Therm. Sci., vol. 63, pp. 55-64, 2013.

[53] A. A. R. Darzi, M. Farhadi, and K. Sedighi, "Numerical study of melting inside concentric and eccentric horizontal annulus," Appl. Math. Model., vol. 36, no. 9, pp. 4080-4086, 2012.

[54] S. Tiari, S. Qiu, and M. Mahdavi, "Discharging process of a finned heat pipe-assisted thermal energy storage system with high temperature phase change material," Energy Convers. Manag., vol. 118, pp. 426-437, 2016. 
[55] V. R. Voller and C. Prakash, "A fixed grid numerical modelling methodology for convection-diffusion mushy region phase-change problems," Int. J. Heat Mass Transf., vol. 30, no. 8, pp. 1709-1719, 1987.

[56] H. L. Wei, J. Mazumder, and T. DebRoy, "Evolution of solidification texture during additive manufacturing," Sci. Rep., vol. 5, pp. 1-7, 2015.

[57] J. Yang et al., "Role of molten pool mode on formability, microstructure and mechanical properties of selective laser melted Ti-6Al-4V alloy," JMADE, vol. 110, pp. 558-570, 2016.

[58] J. Yang, H. Yu, J. Yin, M. Gao, Z. Wang, and X. Zeng, "Formation and control of martensite in Ti-6Al-4V alloy produced by selective laser melting," JMADE, vol. 108, pp. 308-318, 2016.

[59] Z. Wang, K. Guan, M. Gao, X. Li, X. Chen, and X. Zeng, "The microstructure and mechanical properties of deposited-IN718 by selective laser melting," J. Alloys Compd., vol. 513, pp. 518-523, 2012.

[60] Z. Wang, R. Li, L. Wang, J. Liu, W. Jiang, and Y. Shi, "Densification behavior of gas and water atomized 316 L stainless steel powder during selective laser melting," Appl. Surf. Sci., vol. 256, no. 13, pp. 4350-4356, 2010.

[61] A. R. A. Dezfoli, W. S. Hwang, W. C. Huang, and T. W. Tsai, "Determination and controlling of grain structure of metals after laser incidence: Theoretical approach," Sci. Rep., vol. 7, no. 1, pp. 1-11, 2017.

[62] B. Vrancken, L. Thijs, J. P. Kruth, and J. Van Humbeeck, "Microstructure and mechanical properties of a novel $\beta$ titanium metallic composite by selective laser melting," Acta Mater., vol. 68, pp. 150-158, 2014.

[63] L. Thijs, K. Kempen, J. P. Kruth, and J. Van Humbeeck, "Fine-structured aluminium products with controllable texture by selective laser melting of pre-alloyed AISi10Mg powder," Acta Mater., vol. 61, no. 5, pp. 1809-1819, 2013.

[64] T. F. Flint, C. Panwisawas, Y. Sovani, M. C. Smith, and H. C. Basoalto, "Prediction of grain structure evolution during rapid solidification of high energy density beam induced re-melting," Mater. Des., vol. 147, pp. 200-210, 2018.

[65] B. Zhang, H. Liao, and C. Coddet, "Microstructure evolution and density behavior of CP Ti parts elaborated by Self-developed vacuum selective laser melting system," Appl. Surf. Sci., vol. 279, pp. 310-316, 2013.

[66] T.F. Broderick, A.G. Jackson, H. Jones, and F.H. Froes, "The effect of cooling conditions on the microstructure of rapidly solidified Ti-6Al-4V," Metall. Trans. A, vol. 16, no. 16, pp. 1951-1959, 1985.

[67] I. Sen, S. Tamirisakandala, D. B. Miracle, and U. Ramamurty, "Microstructural effects on the mechanical behavior of B-modified Ti-6Al-4V alloys," Acta Mater., vol. 55, no. 15, pp. 4983-4993, 2007. 